John K. Dagsvik

\title{
Aggregation in Matching Markets
}

\begin{abstract}
:
This paper develops aggregate relations for a matching market of heterogeneous suppliers and demanders. The point of departure is the analysis of two-sided matching found in Roth and Sotomayor (1990). Under particular assumptions about the distribution of preferences, the present paper derives asymptotic aggregate relations for the number of realized matches of different types in the presence of flexible contracts (such as a price). Simulation experiments demonstrate that the model also provides excellent predictions in small populations.
\end{abstract}

Keywords: two-sided matching models, discrete choice, market equilibrium, marriage models, the Golden Section.

JEL classification: C78, J41

Acknowledgement: I have benefitted from comments and criticism on earlier versions of this paper by S. Strøm, R. Aaberge, J.J. Heckman, W. Brock, M. Simpson, C. Bollinger, J. Rust, O. Bjerkholt and participants in workshops at the University of Wisconsin, University of Chicago and the Norwegian School of Economics and Business Administration. Thanks to Anne Skoglund for word processing and proof reading.

Address: John K. Dagsvik, Statistics Norway, Research Department, P.O.Box 8131 Dep., N-0033 Oslo, Norway. E-mail: jda@ssb.no 


\section{Introduction}

Many important areas of individual behavior involve the search for a partner in a matching market. Typical examples of matching phenomena are the process of marriage formation, the admission process of students into colleges, and the matching of employees and workers in the labor market. A particular important challenge is to obtain a tractable econometric framework for analyzing matching behavior in a population of heterogeneous agents with preferences that are unknown to the analyst. This is the topic which will be discussed in this paper.

A game-theoretic analysis of the matching problem relevant for matching markets, started with Gale and Shapley (1962) and Shapley and Shubik (1972). See Roth and Sotomayor (1990), for an overview of the literature as well as a theoretical analysis of marriage markets under particular assumptions about the rules of the game. Becker (1981) applies a matching model to study marriage and household economics. His concern is to analyze which men are married to which women under the assumption that the couple derives utility from attributes of the man and the woman.

None of the authors mentioned above consider the problem of developing a mathematically tractable expression for the probability distribution of the number of realized matches as a function of parameters that identify the distribution of agents preferences and the size of the relevant population groups. In the demographic literature, however, several authors have formulated more or less ad hoc models for the number of marriages formed as a function of the number of unmarried males and females in each age group (cf. Hoem, 1969, McFarland, 1972, Pollard, 1977, and Schoen, 1977, Pollak, 1990, Chung, 1994). The only contributions we know of that have attempted to derive a structural aggregate relationship for the distribution of the number of realized matches, is Tinbergen (1956).

Our point of departure is a market with suppliers and demanders. Each agent wishes to form a match with a potential partner which may include specific terms of a contract (such as price, for example). The menu of contract possibilities is finite and given exogenously. The agents are heterogeneous with respect to characteristics (attributes). An agent's characteristics affect his own preferences and enter as attributes in the utility functions of other agents. However, only some of the attributes are observed by the analyst. Each agent has preferences over all potential partners and over the contract menu.

In this paper we demonstrate that particular aggregation results are consistent with the behavioral rules analyzed in Crawford and Knoer (1981). In this case there are no search costs and the number of agents have full information about the attributes of all potential partners, but have no information about their preferences. Under particular assumptions about the distribution of the preferences we show that analytically tractable asymptotic formulae for the number of realized matches between suppliers and demanders for each combination of observable characteristics follow. In Dagsvik (1993) a similar setting was analyzed. However, that paper did not provide a behavioral 
story consistent with the aggregation relations. Note, however, that the aggregate relations derived below are consistent with any algorithm that produces stable matchings as long as there are no search costs and the agents have full information about the attributes of all potential partners.

Other approaches than the present one are found in what is called the job search literature. (See for example Mortensen (1982), (1988), and Diamond and Maskin (1979, 1982), Burdett and Mortensen (1988), and Burdett and Vishwanath (1988).) The essential difference between the theories based on optimal search and the first setting described above is that this setting describes behavior in a market with a finite, known set of potential matching partners. There are no search costs and, ex ante, the agents have no information about their opportunities in the market. They learn about their opportunities while they (costlessly) make/receive offers. In contrast, theory formulations based on optimal search allow for search costs and an unknown set of potential partners. Also the present formulation takes into account the interaction between different types of agent's that result from the competition in the market.

The organization of the paper is as follows: In Section 2 the model setting is described and examples are discussed, and in Section 3 and 4 the matching model with a finite number of agents is analyzed. In Section 5 we extend the model to allow for flexible contracts and a finite number of observable (to the econometrician) categories of suppliers and demanders. In Section 6 we allow for specific correlation patterns in the agents utility functions. In Section 7 some examples are considered, and in the final section the predictions from the aggregate asymptotic expressions are compared with "exact" results generated by a series of simulation experiments.

\section{Demand, supply and realized matches: description of the game}

We consider a market with suppliers and demanders (agents) that wish to form a match with a partner. The agents are heterogeneous with respect to unobserved characteristics, called attributes, and they have preferences over attributes of their potential partners. We shall now discuss the agents behavior in the matching market and a particular market adjustment process towards equilibrium that is perceived as taking place in several stages.

Let us first introduce some basic terminology that concerns the rules of the game in the first setting referred to in the introduction above. The following concepts are borrowed from Roth and Sotomayor (RS) (1990).

A supplier is acceptable to a demander if the supplier prefers to be matched to the demander rather than staying unmatched. Consider a matching denoted by $\mu$ that matches a pair $(s, d)$ who are not mutually acceptable. Then at least one of the agents would prefer to be single rather than being matched to the other. Such a matching $\mu$ is said to be blocked by the unhappy agent. A person who does not obtain a match is said to be self-matched. Consider next a matching $\mu$ such that there exist a 
supplier $\mathrm{s}$ and a demander $\mathrm{d}$ who are not matched to another, but who prefer each other to their assignment at $\mu$ (given the rules of the game). The pair (s,d) will be said to block the matching $\mu$. We say that a matching $\mu$ is stable if it is not blocked by any individual or pair of agents.

Gale and Shapley (cf. RS) have demonstrated that stable matchings exist for every matching market. Specifically they described an algorithm called the "deferred acceptance" procedure which they prove produces a stable matching for any set of preferences provided the preferences are strict. This algorithm goes as follows: First each supplier makes an offer to his favorite demander. Each demander rejects the offer from any supplier who is unacceptable to him, and each demander who receives more than one offer from any supplier rejects all but his most preferred among these. Any supplier whose offer is not rejected at this point is kept "engaged". At any step any supplier who was rejected at the previous step makes an offer to his next choice i.e., to his most preferred demander among those who have not rejected him. Each demander receiving offers rejects any from unacceptable suppliers, and also rejects all but his most preferred among the group of the new offers and any supplier he may have kept engaged from the previous step. The algorithm stops after any step in which no supplier is rejected. The matches are now consummated with each supplier being matched to the demander he is engaged.

The stability argument goes as follows: Suppose that supplier $s$ and demander $d$ are not matched to each other, but $s$ prefers $d$ to his own partner. Then demander $d$ must be acceptable to supplier $\mathrm{s}$, and so he must have made an offer to $\mathrm{d}$ before making an offer to his current matching partner. Since $s$ was not engaged to $d$ when the algorithm stopped, $s$ must have been rejected by $d$ in favor of someone he (d) liked as least as well. Therefore $d$ is matched to a supplier whom $d$ likes at least as well as supplier s, and so $s$ and $d$ do not block the matching. Since the matching is not blocked by any individual or any pair, it is stable. Similarly one could apply a rule where the demanders making offers to the suppliers. However, this would not necessarily produce a matching that is equal to the former one.

To apply the deferred acceptance algorithm requires that the agents' preference lists are known to the analyst. As mentioned above, our concern is, however, to recover the structure of the preferences from observations on realized matchings and the size and composition of the population of agents in the market. In the marriage market literature referred to above it is usually assumed that the agents are fully informed about potentially available partners and that an agent, if rejected, continues to make or receive offers until all possibilities in the market have been explored.

\section{A few examples:}

i) The marriage market. We have already mentioned the need for establishing a marriage - or mating function in two-sex demographic models. The relevance of this problem is discussed in Pollak 
(1990). The results developed below yield tractable functional forms and are therefore well suited for empirical modelling and analysis.

ii) The labor market. Roth and Sotomayor (1990), see also Crawford and Knoer (1981), have focused on the matching processes that take place in the labor market. If we abstract from search and transaction costs the market of medical interns as well as other sectors of the labor market can be modelled within the framework discussed below.

iii) The housing market. The housing market where people buy and sell houses/apartments can also be viewed as a matching market. A typical feature of the market of used houses is that the set of durables (houses) in this market is more or less fixed in the short run. The analogy to the marriage market is immediately realized from the observation that buyers look for sellers to exchange a house at some price. Thus the purpose of a match is simply to exchange a house with a "potential" partner. However, this case is not entirely analogous to the conventional marriage market because many agents operating in this market are both buyers and sellers: A buyer wants to sell his old house and a seller has often just made a purchase of a new house. One way to handle this goes as follows: Note first that it is often the case that the purchase of a new house is made before the old one has been sold. Thus in this stage the agent is uncertain about the price he may obtain in the second stage when offering his old house for sale in the market. In the first stage we can still think of this market as a conventional matching game as described above with the modification that an agent's preference list is evaluated by taking expected utility with respect to future uncertain sale price of the old house. Furthermore, the attributes of the sellers in this market are identified by the attributes of the respective houses offered for sale while the attributes of the buyers may be variables such as collateral and ability to realize the purchase quickly.

For the sake of focusing on the basic idea of the approach we shall in the next section derive a model for the probability of realizing a match in the simplest case in which all the suppliers are observationally identical to the analyst, as are also all the demanders.

\section{Aggregation in the special case where suppliers and demanders each are observationally identical to the analyst}

Let $\mathrm{N}$ be the number of suppliers and $\mathrm{M}$ the number of demanders. In the following we shall employ small superscripts $s$ and $d$ as indices for a particular supplier, $s$, and demander, $d$, and sometimes capital superscripts, $S$ and $D$, to indicate supply and demand. Let $U^{\text {sd }}$ be the utility of supplier s of a match with demander d. Let $U_{0}^{s}$ be the utility of supplier s of being self-matched. Similarly let $V^{d s}$ be the utility of demander $d$ of a match with supplier $s$ and let $V_{0}^{d}$ be the utility of demander $d$ of being self-matched. We assume that 


$$
\mathrm{U}_{0}^{\mathrm{s}}=\alpha \varepsilon_{0}^{\mathrm{s}}, \quad \mathrm{U}^{\mathrm{sd}}=\varepsilon^{\mathrm{sd}},
$$

and

$$
V_{0}^{d}=\beta \eta_{0}^{d}, \quad V^{d s}=\eta^{d s}
$$

where $\alpha$ and $\beta$ are systematic terms (unknown parameters) that are common to all the suppliers and demanders, respectively, while $\left\{\varepsilon^{\text {sd }}\right\},\left\{\varepsilon_{0}^{s}\right\},\left\{\eta^{\text {ds }}\right\}$ and $\left\{\eta_{0}^{\text {d }}\right\}$ are i.i.d. random tasteshifters (random to the observer). Moreover, we assume that

$$
P\left(\varepsilon^{s d} \leq y\right)=P\left(\eta^{d s} \leq y\right)=P\left(\varepsilon_{0}^{s} \leq y\right)=P\left(\eta_{0}^{d} \leq y\right)=\exp \left(-\frac{1}{y}\right) .
$$

The assumption (3.3) is consistent with the "Independence from Irrelevant Alternatives" (IIA) axiom, cf. Ben-Akiva and Lerman (1985). If we had chosen an additive formulation in (3.1) and (3.2) then the c.d.f. in (3.3) would have had to be replaced by $\exp \left(-\mathrm{e}^{-\mathrm{y}}\right)$ to be consistent with IIA. This is easily realized by taking the logarithm of (3.1) and (3.2). The choice between the multiplicative and the additive formulation is only a matter of taste since they are, from a theoretical point of view, completely equivalent. Since the set of agents who realize a match is independent of the actual matching procedure (provided the matching is stable) we do not have to worry about the particular properties of the algorithm - be it the deferred acceptance algorithm or other rules of the game as long as preferences are strict. Since the random terms in the utility functions are generated by c.d.f. that are absolutely continuous it follows that preferences are strict with probability one.

In the final stage (when the matches are consummated), let $D^{s}$ be the set of demanders that have not rejected supplier $\mathrm{s}$ in previous stages of the game when the suppliers are making the offers. Let $C^{d}$ consist of all the offers demander $d$ has received when the suppliers are making the offers. While $C^{d}$ clearly consists of all the suppliers that are feasible to demander d, all the demanders in $D^{s}$ are not necessarily feasible to supplier s. However, if there is a demander $d^{*}$ in $D^{s}$ that is not feasible to supplier $\mathrm{s}$ he would be ranked below some other demander that is feasible to $\mathrm{s}$, since otherwise $\mathrm{s}$ would have made an offer to $\mathrm{d}^{*}$ and $\mathrm{d}^{*}$ would have rejected $s$ at a previous stage. Therefore, $\mathrm{D}^{s}$ is equivalent to the choice set of supplier $\mathrm{s}$ in the sense that his choice from $\mathrm{D}^{\mathrm{s}}$ would be the same as the choice from his choice set.

Before we plunge into the formal analysis it may be instructive to discuss the intuition behind the approach. To this end we will assume for a moment that when the population is large one can ignore variations in the number of consummated matches as a result of variations in the random tasteshifters. In the formal analysis below we shall prove that this is so. Let $\mathrm{m}$ be the number (mean number) of demanders in $D^{s}$ and $n$ the number of suppliers in $C^{d}$. Since the population in large $m$ and $n$ 
will not depend on s and d, respectivley. It follows from (3.1) to (3.3) that the probability that supplier $s$ shall rank a particular demander in $\mathrm{D}^{\mathrm{s}}$ on top equals

$$
\frac{1}{\alpha+m}
$$

Moreover, since there are $\mathrm{N}$ suppliers and the suppliers have identically distributed preferences, the probability that a supplier shall be interested in a match with demander $d$ equals $n / N$. In equilibrium we thus have

$$
\frac{\mathrm{n}}{\mathrm{N}}=\frac{1}{\alpha+\mathrm{m}}
$$

By symmetry, we also have

$$
\frac{\mathrm{m}}{\mathrm{M}}=\frac{1}{\beta+\mathrm{n}}
$$

The probability that a supplier and a demander shall realize a match with each other is the product of the probabilities that the supplier and the demander are interested in each other. Since the probability that supplier $s$ shall make an offer to demander $d$ equals $n / N$ and the probability that demander $d$ shall accept this offer equals $\mathrm{m} / \mathrm{M}$ the (equilibrium) number of realized matches therefore equals $\mathrm{MN} \cdot(\mathrm{m} / \mathrm{M})(\mathrm{n} / \mathrm{N})=\mathrm{mn}$. Eq. (3.4) and (3.5) determine $\mathrm{m}$ and $\mathrm{n}$ uniquely as a function of $\alpha$, $\beta, M$ and $N$.

The treatment above ignores the fact that the sets $C^{d}$ and $D^{s}$ are stochastic and consequently there are complicated stochastic dependencies between the different opportunity sets $\left\{C^{d}, D^{s}\right\}$. Let us now therefore turn to a more rigorous argument.

Let $I^{\text {sd }}=1$ if $d \in D^{s}$ and zero otherwise, and define $I^{d s}=1$ if $s \in C^{d}$ and zero otherwise. Then

$$
\mathrm{m}^{\mathrm{s}} \equiv \sum_{\mathrm{k}} \mathrm{I}^{\mathrm{sk}} \text { and } \mathrm{n}^{\mathrm{d}} \equiv \sum_{\mathrm{k}} \mathrm{I}^{\mathrm{dk}}
$$

are the number of demanders in $D^{s}$ and suppliers in $C^{d}$. Furthermore, define

$$
\mathrm{m}^{\text {sd }} \equiv \sum_{\mathrm{k} \neq \mathrm{d}} \mathrm{I}^{\mathrm{sk}} \text { and } \mathrm{n}^{\mathrm{ds}} \equiv \sum_{\mathrm{k} \neq \mathrm{s}} \mathrm{I}^{\mathrm{dk}}
$$

which are the number of demanders in $D^{s} \backslash\{d\}$ and suppliers in $C^{d} \backslash\{s\}$.

Define conditional supply and demand probabilities as

$$
\mathrm{g}^{\mathrm{s}} \equiv \mathrm{P}\left(\mathrm{U}^{\mathrm{sd}}=\max \left(\max _{\mathrm{r} \in \mathrm{D}^{\mathrm{s}}} \mathrm{U}^{\mathrm{sr}}, \mathrm{U}_{0}^{\mathrm{s}}\right) \mid \mathrm{d} \in \mathrm{D}^{s}\right)=\mathrm{E}\left(\mathrm{I}^{\mathrm{ds}} \mid \mathrm{d} \in \mathrm{D}^{\mathrm{s}}\right)
$$


and

$$
g^{D} \equiv P\left(V^{d s}=\max \left(\max _{r \in C^{d}} V^{d r}, V_{0}^{d}\right) \mid s \in C^{d}\right)=E\left(I^{s d} \mid s \in C^{d}\right)
$$

Since the distribution of the utilities does not depend on characteristics of the individual agents, (3.6) and (3.7) are independent of $s$ and $d$. Obviously, $g^{S}\left(g^{D}\right)$ is the probability that supplier $s$ (demander d), in the final stage, shall make an offer to demander $d$ (supplier s) given that demander $d$ (supplier s) is available in the final stage. From assumptions (3.1) to (3.3) it follows that

$$
P\left(U^{s d}=\max \left(\max _{r \in D^{s}} U^{s r}, U_{0}^{s}\right) \mid m^{s d}, d \in D^{s}\right)=\frac{1}{\alpha+1+m^{s d}}
$$

By (3.8) we get

$$
g^{s}=E\left(\frac{1}{\alpha+1+m^{\text {sd }}}\right)
$$

where the expectation is taken with respect to $\mathrm{m}^{\text {sd }}$. Similarly, we get

$$
P\left(V^{d s}=\max \left(\max _{r \in C^{d}} V^{d r}, V_{0}^{d}\right) \mid s \in C^{d}, n^{d s}\right)=\frac{1}{\beta+1+n^{d s}}
$$

from which follows that

$$
g^{D}=E\left(\frac{1}{1+\beta+n^{d s}}\right)
$$

Furthermore we have that

$$
\mathrm{m} \equiv \mathrm{Em}^{\mathrm{s}}=\mathrm{Mg}^{\mathrm{D}}
$$

and

$$
n \equiv n^{d}=N g^{s}
$$

We shall now study the (aggregate) stable (equilibrium) solution when $\mathrm{N}$ and $\mathrm{M}$ are large. Specifically, we shall allow $N$ and $M$ to increase such that $N / M$ tends towards a constant. To obtain asymptotic results we need the following Lemma. 


\section{Lemma 1}

Let $\tau_{1}$ and $\tau_{2}$ be any non-negative real number. Then

$$
\frac{1}{1+\tau_{1}+(M-1) g^{D}} \leq E\left(\frac{1}{1+\tau_{1}+m^{s d}}\right) \leq \frac{1}{\tau_{1}+\frac{M-1}{1+\beta+(N-1) g^{S}}}
$$

and

$$
\frac{1}{1+\tau_{2}+(N-1) g^{s}} \leq E\left(\frac{1}{1+\tau_{2}+n^{d s}}\right) \leq \frac{1}{\tau_{2}+\frac{N-1}{1+\alpha+(M-1) g^{D}}}
$$

The proof in this Lemma is given in the appendix.

\section{Theorem 1}

Suppose that $N$ and $M$ increase such that $N / M$ tends towards a constant, $\psi^{2}$. Moreover, assume that $\alpha$ and $\beta$ depend on $N$ such that $\bar{\alpha} \equiv \lim _{N \rightarrow \infty} \alpha(N) / \sqrt{M}$ and $\bar{\beta} \equiv \lim _{N \rightarrow \infty} \beta(N) / \sqrt{N}$ exist. If the agents preferences are given by (3.1) and (3.2), then

$$
\begin{aligned}
& \operatorname{plim}_{M \rightarrow \infty} \frac{m^{s d}}{\sqrt{M}}=\operatorname{plim}_{M \rightarrow \infty} \frac{m^{s}}{\sqrt{M}}=u, \\
& \operatorname{plim}_{N \rightarrow \infty} \frac{n^{d s}}{\sqrt{N}}=\underset{N \rightarrow \infty}{p \lim } \frac{n^{d}}{\sqrt{N}}=v,
\end{aligned}
$$

where

$$
v \equiv \operatorname{plim}_{N \rightarrow \infty} g^{S} \sqrt{N} \text { and } u \equiv \operatorname{plim}_{M \rightarrow \infty} g^{D} \sqrt{M}
$$

exist and are uniquely determined by the system of equations

$$
v=\frac{\psi}{\bar{\alpha}+u}
$$

and

$$
u=\frac{1 / \psi}{\bar{\beta}+v}
$$


The proof of Theorem 1 is given in the appendix.

Consider now the probability, $\mathrm{q}^{\mathrm{S}}\left(\mathrm{q}^{\mathrm{D}}\right)$ that a supplier (demander) shall obtain a match with any demander (supplier). Clearly supplier $s$ will obtain a match if the utility of being matched to some demander in $D^{s}$ is greater than being self-matched. From the assumptions (3.1)-(3.3) it follows that

$$
\mathrm{P}\left(\mathrm{U}_{0}^{\mathrm{s}}<\max _{\mathrm{d} \in \mathrm{D}^{s}} \mathrm{U}^{\mathrm{sd}} \mid \mathrm{m}^{\mathrm{s}}\right)=\frac{\mathrm{m}^{\mathrm{s}}}{\alpha+\mathrm{m}^{s}}
$$

and

$$
P\left(V_{0}^{d}<\max _{s \in C^{d}} V^{d s} \mid n^{d}\right)=\frac{n^{d}}{\beta+n^{d}} .
$$

Thus

$$
q^{s}=E\left(\frac{m^{s}}{\alpha+m^{s}}\right)
$$

and

$$
q^{D}=E\left(\frac{n^{d}}{\beta+n^{d}}\right)
$$

\section{Corollary 1}

Under the assumptions of Theorem 1 the (asymptotic) number of realized matches, $X$, satisfies the equation

$$
\alpha \beta X=(N-X)(M-X),
$$

of which the only acceptable solution is given by

$$
X=\frac{1}{2}\left(\alpha \beta+M+N-\sqrt{(\alpha \beta+M+N)^{2}-4 M N}\right) .
$$

Proof:

From Theorem 1, (3.20) and (3.21) it follows that

$$
\lim _{N \rightarrow \infty} q^{s}=\lim _{N \rightarrow \infty} E\left(\frac{m^{s} / \sqrt{M}}{\alpha / \sqrt{M}+m^{s} / \sqrt{M}}\right)=\frac{u}{\bar{\alpha}+u}
$$


and

$$
\lim _{M \rightarrow \infty} q^{D}=\lim _{M \rightarrow \infty} E\left(\frac{n^{d} / \sqrt{N}}{\beta / \sqrt{N}+n^{d} / \sqrt{N}}\right)=\frac{v}{\bar{\beta}+v}
$$

where $\bar{\alpha}=\lim _{N \rightarrow \infty} \alpha / \sqrt{M}$ and $\bar{\beta}=\lim _{N \rightarrow \infty} \beta / \sqrt{N}$.

By combining (3.24), (3.16) and (3.25) and (3.17) we obtain

$$
v=\left(1-\lim _{N \rightarrow \infty} q^{s}\right) \psi / \alpha
$$

and

$$
u=\left(1-\lim _{M \rightarrow \infty} q^{D}\right) / \psi \bar{\beta}
$$

When (3.26) and (3.27) are inserted into (3.26) we get

$$
\left(1-\lim _{M \rightarrow \infty} q^{D}\right)\left(1-\lim _{N \rightarrow \infty} q^{s}\right)=\psi \bar{\alpha} \bar{\beta} \lim _{N \rightarrow \infty} q^{s}
$$

Since $\lim _{N \rightarrow \infty} q^{S}=\psi^{2} \lim _{M \rightarrow \infty} q^{D}$ and $X=N q^{S}$, (3.22) follows. Since (3.23) is the only solution of (3.22) within $(0, \min (M, N))$, it is the only acceptable solution.

From (3.23) we realize that when $N=M$ and $\bar{\alpha}$ and $\bar{\beta}$ are close to zero then $X$ is close to $N$ when $\mathrm{N}$ is large. At first glanse this may seem surprising, since the population of suppliers and demanders have the same size. The explanation is that since the utility functions have i.i.d. random tasteshifters then for sufficiently large $\mathrm{N}$ the probability that a supplier will find a very attractive demander which ranks the supplier on top (among all suppliers) will be close to one.

\section{A special case: The Golden Section}

It has long been realized that certain shapes of rectangle seem to the human eye to be aesthetically more satisfactory than others. Indeed, given a large range of rectangular shapes to choose from, most people, it is said, will tend to choose as most satisfactory one which length bears to its width the same ratio as the sum of the length and the width bear to the length alone. The resulting ratio is called the Golden Section $(\varphi)$ and it is determined by the equation

$$
\varphi^{2}=\varphi+1
$$


i.e., $\varphi=(1+\sqrt{5}) / 2$.

The Golden Section is exhibited in the Athenian Parthenon and a number of other buildings of classical antiquity and it is also found in the Egyptian Great Pyramid as the ratio between the slopeheight and the half-base (within .001 of the Golden Section). Moreover, it is found at the entrance of the tomb of Ramses IX and on the walls of the colonnade of Amon in the Temple of Luxor (cf. Schwaller de Lubicz, 1985 and Lemesurier, 1977).

The Golden Section is also linked to the so-called Fibonacci Series where each number equals the sum of its two predecessors. It is found with surprising frequency in nature, for example in pattern of plant growth, in flower-petal arrangements, in the laws of Mendelian heredity and in the ratios between planetary orbits.

It is intriguing that the (inverse) Golden Section also emerges as a solution of (3.15) and (3.16) in the following special case with $M=N$ and $\bar{\alpha}=\bar{\beta}=1$, which means that $\alpha=\beta=\sqrt{N}$. Recall that the assumption that $\alpha / \sqrt{M}$ and $\beta / \sqrt{N}$ tend towards constants, $\bar{\alpha}$ and $\bar{\beta}$, when $M$ and $N$ increases mean that the fraction of people that prefer to be self-matched asymptotically remains the same when the population grows. When $N=1$ the last assumption, $\bar{\alpha}=\bar{\beta}=1$, means that the probability of preferring a match over being self-matched is equal to $1 / 2$. Thus, when only one potential partner is present the agents are, on average, indifferent between the two alternatives "being matched" and "self-matched". Under these assumptions it follows that $g^{S}=g^{D}$ and $q^{S}=q^{D}$. Form (3.15) and (3.16) we get that $u=v=1 / \varphi$. From (3.21) we obtain that

$$
q^{S}=q^{D}=1 / \varphi^{2}
$$

The probability of being self-matched equals

$$
1-q^{S}=1-1 / \varphi^{2}=1 / \varphi
$$

The last equality in (4.3) follows from (4.1).

\section{The general case with flexible contracts and several observable categories of suppliers and demanders}

In this section we shall modify the description in Sections 2 and 3 so as to allow for flexible contracts. Relevant examples are tuition fees and grades in the market for education, and wages and non-pecuniary conditions in the labor market.

One particular rule of the game we shall consider in the present section is a simple extension of the deferred acceptance algorithm discussed in Section 3: Let us modify the list of rank orderings by 
considering each supplier's (demander's) list of rank ordering of all possible combinations of contract and demander (supplier) attributes. Thus, when a supplier (say) makes an offer to a demander this offer includes specific contract terms. With this modification the game proceeds as the deferred acceptance algorithm described in Section 2. The algorithm described above has been analyzed theoretically by Crawford and Knoer (1981).

In the present section we also assume that a subset of the attributes are observable to the econometrician such that the agents can be grouped into a finite number of (observable) categories. Specifically, let $M_{j}$ be the number of demanders of type $j, j=1,2, \ldots, D$, and $N_{i}$ the number of suppliers of type $i, i=1,2, \ldots, S$. The total number of possible contracts is also finite and equal to $\mathrm{W}$, the total number of suppliers and demanders are $\mathrm{N}$ and $\mathrm{M}$. The assumption of finite $\mathrm{W}$ is made for simplicity and can easily be relaxed.

Let $U_{i j}^{s d}(w)$ be the utility of supplier s of type $i$ of a match with demander $d$ of type $j$ with contract $w$. Let $U_{i 0}^{s}$ be the utility of supplier s of type $i$ of being self-matched. We assume that

$$
\mathrm{U}_{\mathrm{i} 0}^{\mathrm{s}}=\mathrm{a}_{\mathrm{i} 0} \varepsilon_{\mathrm{i} 0}^{\mathrm{s}}, \mathrm{U}_{\mathrm{ij}}^{\mathrm{sd}}(\mathrm{w})=\mathrm{a}_{\mathrm{ij}}(\mathrm{w}) \varepsilon_{\mathrm{ij}}^{\mathrm{sd}}(\mathrm{w})
$$

where $\left\{\mathrm{a}_{\mathrm{ij}}(\mathrm{w})\right\}$ and $\left\{\mathrm{a}_{\mathrm{i} 0}\right\}$ are systematic terms and $\left\{\varepsilon_{\mathrm{ij}}^{\mathrm{sd}}(\mathrm{w})\right\}$ as well as $\left\{\varepsilon_{\mathrm{i} 0}^{\mathrm{s}}\right\}$ are i.i.d. random tasteshifters.

On the demand side the description is completely analogous. Thus

$$
V_{j 0}^{d}=b_{j 0} \eta_{j 0}^{d}, V_{j i}^{d s}(w)=b_{j i}(w) \eta_{j i}^{d s}(w)
$$

is the utility function of demander $d$ that corresponds to (5.1).

Let $D_{i j}^{s}(w)$ be the equilibrium set of demanders of type $j$ that has not rejected a match offered by supplier $s$ under contract $w$. Similarly, let $C_{j i}^{d}(w)$ be the equilibrium set of all the offers of type $i$ demander $d$ of type $j$ under contract $w$ has received. If the rules of the game is given by the deferred acceptance algorithm then $\left\{C_{\mathrm{ji}}^{\mathrm{d}}(\mathrm{w})\right\}$ and $\left\{\mathrm{D}_{\mathrm{ij}}^{\mathrm{s}}(\mathrm{w})\right\}$ correspond to the choice sets in the final stage of the game. However, as discussed in Section 2 a more general interpretation is possible. Let $\mathrm{m}_{\mathrm{ij}}^{\mathrm{s}}(\mathrm{w})$ and $n_{j i}^{d}(w)$ be the number of demanders in $D_{i j}^{s}(w)$ and suppliers in $C_{j i}^{d}(w)$. We shall investigate below the conditions under which (aggregate) market equilibrium exists when the population of suppliers and demanders are large.

Similarly to (3.3) we assume that $\varepsilon_{i j}^{s d}(w), \varepsilon_{j i}^{d s}(w), \varepsilon_{i 0}^{s}, \varepsilon_{j 0}^{d}, s=1,2, \ldots, N_{i}, i=1,2, \ldots, S$, $d=1,2, \ldots, M_{j}, j=1,2, \ldots, D, w=1,2, \ldots, W$, are i.i.d. with 


$$
P\left(\varepsilon_{i j}^{s d}(w) \leq y\right)=P\left(\eta_{j i}^{d s}(w) \leq y\right)=P\left(\varepsilon_{i 0}^{s} \leq y\right)=P\left(\eta_{j 0}^{d} \leq y\right)=\exp \left(-\frac{1}{y}\right) .
$$

Consider the behavior of supplier s conditional on the choice set $D_{i j}^{s}(w)$. Let $g_{i j}^{s}(w)$ be the probability that supplier $s$ of type $i$ will prefer demander $d$ of type $j$ under contract $w$. We shall call $\left\{g_{i j}^{s}(w)\right\}$ the conditional supply probabilities. Specifically, for $d \in D_{i j}^{s}(w)$

$$
\begin{aligned}
& \mathbf{g}_{\mathrm{ij}}^{\mathbf{s}}(w) \equiv P\left(U_{\mathrm{ij}}^{s d}(w)=\max \left(\max _{k, \mathrm{r}}\left(\max _{q \in D_{\mathrm{ik}}^{\mathrm{s}}(\mathrm{r})} U_{\mathrm{ik}}^{\mathrm{sq}}(\mathrm{r})\right), \mathrm{U}_{\mathrm{i} 0}^{\mathrm{s}}\right) \mid \mathrm{d} \in \mathrm{D}_{\mathrm{ij}}^{\mathrm{s}}(\mathrm{w})\right) \\
& =E\left(\frac{a_{i j}(w)}{a_{i 0}+a_{i j}(w)+\left(m_{i j}^{s}(w)-1\right) a_{i j}(w)+\sum_{(k, r) \neq(j, w)} m_{i k}^{s}(r) a_{i k}(r)} \mid d \in D_{i j}^{s}(w)\right) \\
& =E\left(\frac{a_{i j}(w)}{\sum_{k} \sum_{r>0} a_{i k}(r) m_{i k}^{s}(r)+a_{i 0}} \mid d \in D_{i j}^{s}(w)\right) \text {. }
\end{aligned}
$$

The derivation of (5.4) is completely analogous to the derivation of the choice probabilities of the extreme value random utility model, see Ben-Akiva and Lerman op cit. Similarly, the conditional demand probabilities are given by

$$
g_{j i}^{D}(w)=E\left(\frac{b_{j i}(w)}{b_{j 0}+\sum_{k} \sum_{r>0} n_{j k}^{d}(r) b_{j k}(r)} \mid s \in C_{j i}^{d}(w)\right)
$$

To facilitate further calculations it will be convenient to introduce additional notation. Let $I_{i j}^{s d}(w)=1$ if $d \in D_{i j}^{s}(w)$ and zero otherwise and define $m_{i j}(w)=E m_{i j}^{s}(w)$ and $n_{j i}(w)=E n_{j i}^{d}(w)$.

Obviously we have

$$
m_{i j}(w) \equiv E m_{i j}^{s}(w)=M_{j} g_{j i}^{D}(w)
$$

and

$$
n_{j i}(w) \equiv E n_{j i}^{d}(w)=N_{i} g_{i j}^{s}(w)
$$

The equations (5.4) to (5.7), hold under the deferred acceptance game as well as in other games that produce stable matchings. By letting $\left\{\mathrm{N}_{\mathrm{i}}\right\}$ and $\left\{\mathrm{M}_{\mathrm{j}}\right\}$ increase towards infinity one can examine the asymptotic properties of this system, similarly to the analysis in Section 3. 
Obviously, $E I_{i j}^{s d}(w)=m_{i j}(w) / M_{j}$, since

$$
\mathrm{m}_{\mathrm{ij}}^{\mathrm{s}}(\mathrm{w})=\sum_{\mathrm{u}=1}^{\mathrm{M}_{\mathrm{j}}} \mathrm{I}_{\mathrm{ij}}^{\mathrm{su}}(\mathrm{w})
$$

We have

$$
\begin{aligned}
& E\left(m_{i j}^{s}(w) \mid d \in B_{i j}^{s}(w)\right)=E\left(m_{i j}^{s}(w) \mid I_{i j}^{s d}(w)=1\right) \\
& =\sum_{u} E\left(I_{i j}^{s u}(w) \mid I_{i j}^{s d}(w)=1\right)=1+\sum_{u \neq d} E I_{i j}^{s u}(w)=1+\left(M_{j}-1\right) \frac{m_{i j}(w)}{M_{j}} .
\end{aligned}
$$

Also, for $r \neq w$,

$$
E\left(m_{i j}^{s}(r) \mid d \in B_{i j}^{s}(w)\right)=\sum_{u} E\left(I_{i j}^{s u}(r) \mid I_{i j}^{s d}(w)=1\right)=\left(M_{j}-1\right) \frac{m_{i j r}}{M_{j}}
$$

because

$$
E\left(I_{i j}^{s u}(r) \mid I_{i j}^{s d}(w)=1\right)=0
$$

due to the fact that $I_{\mathrm{ij}}^{\text {sd }}(k)$ can only be different from zero for one $k$. Finally, we have

$$
E\left(m_{i k}^{s}(r) \mid I_{i j}^{s d}(w)\right)=m_{i k}(r)
$$

when $k \neq j$. Now by a first order Taylor approximation and taking account of (5.9), (5.10) and (5.11), it follows from (5.4) that

$$
\begin{aligned}
& g_{i j}^{s}(w) \cong \frac{a_{i j}(w)}{\sum_{k} \sum_{r>0} a_{i k}(r) E\left(m_{i k}^{s}(r) \mid d \in B_{i j}^{s}(w)\right)+a_{i 0}} \\
& =\frac{a_{i j}(w)}{\sum_{k} \sum_{r>0} a_{i k}(r) m_{i k}(r)+a_{i j}(w)-\sum_{r>0} a_{i j}(r) m_{i j}(r) / M_{j}+a_{i 0}} .
\end{aligned}
$$

Similarly, it follows from (5.6) that

$$
g_{j i}^{D}(w) \cong \frac{b_{j i}(w)}{\sum_{k} \sum_{r>0} b_{j k}(r) n_{j k}(r)+b_{j i}(w)-\sum_{r>0} b_{j i}(r) n_{j i}(r) / N_{i}+a_{i 0}} .
$$

Since $\left\{\mathrm{N}_{\mathrm{i}}\right\}$ and $\left\{\mathrm{M}_{\mathrm{j}}\right\}$ are assumed to be large, it follows that $\left(\mathrm{m}_{\mathrm{ij}}(\mathrm{w})+1\right) / \mathrm{m}_{\mathrm{ij}}(\mathrm{w}) \cong\left(\mathrm{n}_{\mathrm{ji}}(\mathrm{w})+1\right) / \mathrm{n}_{\mathrm{ji}}(\mathrm{w}) \cong 1$, and $\left(\mathrm{N}_{\mathrm{i}}-1\right) / \mathrm{N}_{\mathrm{i}} \cong\left(\mathrm{M}_{\mathrm{j}}-1\right) / \mathrm{M}_{\mathrm{j}} \cong 1$, and that the 
approximations in (5.12) and (5.13) are close. We shall therefore henceforth replace "ミ" by "=". From (5.12), (5.13), (5.6) and (5.7) we therefore get

$$
\begin{aligned}
& m_{i j}(w)=\frac{M_{j} b_{j i}(w)}{B_{j}}, \\
& n_{j i}(w)=\frac{N_{i} a_{i j}(w)}{A_{i}},
\end{aligned}
$$

for $\mathrm{i}=1,2, \ldots, \mathrm{S}, \mathrm{j}=1,2, \ldots, \mathrm{D}$, and $\mathrm{w}=1,2, \ldots, \mathrm{W}$, where

$$
A_{i}=a_{i 0}+\sum_{k} \sum_{r>0} a_{i k}(r) m_{i k}(r)
$$

and

$$
B_{j}=b_{j 0}+\sum_{k} \sum_{r>0} b_{j k}(r) n_{j k}(r)
$$

We shall discuss the problem of existence and uniqueness of a solution of (5.14) to (5.17) in the next section. Another crucial problem is how the approximation error in (5.12) and (5.13) depend on $\left\{\mathrm{N}_{\mathrm{i}}\right\}$ and $\left\{\mathrm{M}_{\mathrm{j}}\right\}$. We have conducted a series of simulation experiments to throw light on this issue. The results (cf. Section 9) show that, on average, the approximation is rather small.

Let us now consider the probability of realizing a match with a particular contract. Given that supplier $s$ belongs to type $i$ and demander $d$ belongs to type $j$, the probability that a match between a supplier $s$ of type $i$ and a demander $d$ of type $j$ under contract $w$ shall occur is equal to the product between the respective conditional supply and demand probabilities, $g_{\mathrm{ij}}^{\mathrm{S}}(w)$ and $g_{\mathrm{ji}}^{\mathrm{D}}(w)$. The probability that supplier $s$ of type $i$ shall obtain a match under contract w with any demander of type $j$, $q_{i j}^{s}(w)$, is therefore equal to

$$
q_{i j}^{S}(w)=g_{i j}^{S}(w) g_{j i}^{D}(w) M_{j}
$$

Similarly, the mean number of matches under contract $w$ where the supplier is of type $i$ and the demander is of type $\mathrm{j}, \mathrm{X}_{\mathrm{ij}}(\mathrm{w})$, equals

$$
X_{i j}(w)=g_{i j}^{S}(w) g_{j i}^{D}(w) N_{i} M_{j}
$$

Consequently, we obtain

$$
X_{i j}(w)=m_{i j}(w) n_{j i}(w)=\frac{a_{i j}(w) b_{j i}(w) M_{j} N_{i}}{A_{i} B_{j}}
$$


for $i=1,2, \ldots, S, j=1,2, \ldots, D, w=1,2, \ldots, W$.

When (5.14) is inserted into (5.16) and (5.15) is inserted into (5.17) we obtain that $\left\{A_{i}\right\}$ and $\left\{B_{j}\right\}$ satisfy the equations

$$
A_{i}=a_{i 0}+\sum_{k} \frac{c_{i k} M_{k}}{B_{k}}
$$

and

$$
B_{j}=b_{j 0}+\sum_{k} \frac{c_{k j} N_{k}}{A_{k}}
$$

where

$$
c_{i j}=\sum_{r>0} a_{i j}(r) b_{j i}(r)
$$

The respective mean number of self-matched suppliers and demanders, $\mathrm{X}_{\mathrm{i} 0}^{\mathrm{S}}, \mathrm{X}_{\mathrm{j} 0}^{\mathrm{D}}$, are given by

$$
X_{i 0}^{S}=\frac{a_{i 0} N_{i}}{A_{i}}
$$

and

$$
X_{j 0}^{D}=\frac{b_{j 0} M_{j}}{B_{j}} .
$$

From Theorem 2 below it follows that the equations (5.21) and (5.22) have a unique solution.

\section{Extensions}

In the derivations above we assumed that the random components of the utility functions were independent and extreme value distributed. We shall now relax some of these assumptions and we start with the simple setting discussed in Section 3.

\subsection{Observationally identical suppliers and demanders}

We shall now allow the taste-shifters associated with potential partners to be correlated. This may be desirable because there may be unobservable factors that affect the utility for potential partners which are correlated (across the potential partners). To this end we now postulate that the vector $\left(\varepsilon^{s 1}, \varepsilon^{s 2}, \ldots, \varepsilon^{s \mathrm{M}}\right)$ is distributed according to a type I multivariate extreme value distribution given by 


$$
P\left(\bigcap_{d}\left(\varepsilon^{s d}<y_{d}\right)\right)=\exp \left(-\left(\sum_{d} y_{d}^{-1 / \theta_{1}}\right)^{\theta_{1}}\right)
$$

(cf. Ben-Akiva and Lerman, 1985), where $\theta_{1} \in(0,1]$ is a constant. The particular version given in (6.1) takes into account that the players are "anynomous" to that the taste-shifters are exchangable.

Moreover, $\theta_{1}$ can be interpreted as

$$
\operatorname{corr}\left(\varepsilon^{s d}, \varepsilon^{s k}\right)=1-\theta_{1}^{2}
$$

for $\mathrm{k} \neq \mathrm{d}$. Similarly, we assume that

$$
P\left(\bigcap_{s}\left(\eta^{d s}<y_{s}\right)\right)=\exp \left(-\left(\sum_{s} y_{s}^{-1 / \theta_{2}}\right)^{\theta_{2}}\right)
$$

where $\theta_{2} \in(0,1]$. However, we assume that $\varepsilon_{0}^{s}$ is independent of $\varepsilon^{\text {sd }}$ and $\eta^{\mathrm{ds}}$ is independent of $\eta_{0}^{\mathrm{d}}$, where the c.d.f. of $\varepsilon_{0}^{s}$ and $\eta_{0}^{d}$ is given by (3.3). Thus when $\theta_{1}$ and $\theta_{2}$ are less than one it means that different potential partners are perceived as more "similar" to the individual than the alternatives "being selfmatched" and "being matched" to some potential partners. In case $\theta_{1}$ and $\theta_{2}$ are close to zero the potential partners appear to be almost identical to the individual. Under assumptions (3.1), (3.2), (6.1) and (6.3), it follows readily that

$$
P\left(U^{s d}=\max \left(\max _{r \in D^{s}} U^{s r}, U_{0}^{s}\right) \mid m^{s d}, d \in D^{s}\right)=\frac{\left(1+m^{s d}\right)^{\theta_{1}-1}}{\alpha+\left(1+m^{s d}\right)^{\theta_{1}}}
$$

and

$$
P\left(V^{d s}=\max \left(\max _{r \in C^{d}} V^{d r}, V_{0}^{d}\right) \mid n^{d s}, s \in C^{d}\right)=\frac{\left(1+n^{d s}\right)^{\theta_{2}-1}}{\beta+\left(1+n^{d s}\right)^{\theta_{2}}} .
$$

Similarly to (3.9) and (3.11) we therefore obtain

$$
g^{s}=E\left(\frac{\left(1+m^{s d}\right)^{\theta_{1}-1}}{\alpha+\left(1+m^{s d}\right)^{\theta_{1}}}\right)
$$

and

$$
g^{D}=E\left(\frac{\left(1+n^{d s}\right)^{\theta_{2}-1}}{\beta+\left(1+n^{d s}\right)^{\theta_{2}}}\right)
$$


where the expectation is taken with respect to $\mathrm{m}^{\text {sd }}$ and $\mathrm{n}^{\mathrm{ds}}$. As in Theorem 1 , it can be demonstrated that the asymptotic values of $m$ and $n$ are given by

$$
n \cong N g^{s}=N E\left(\frac{\left(1+m^{s d}\right)^{\theta_{1}-1}}{\alpha+\left(1+m^{s d}\right)^{\theta_{1}}}\right) \cong \frac{N m^{\theta_{1}-1}}{\alpha+m^{\theta_{1}}}
$$

and

$$
\mathrm{m} \cong \mathrm{Mg}^{\mathrm{D}}=\operatorname{ME}\left(\frac{\left(1+\mathrm{n}^{\mathrm{ds}}\right)^{\theta_{2}-1}}{\beta+\left(1+\mathrm{n}^{\mathrm{ds}}\right)^{\theta_{2}}}\right) \cong \frac{M n^{\theta_{2}-1}}{\beta+n^{\theta_{2}}}
$$

Asymptotically, the probability that supplier s shall obtain a match with any demander equals $\mathrm{g}^{\mathrm{S}} \mathrm{m}$, because $\mathrm{m}$ is (asymptotically) the number of demander available to supplier s. Since there are $\mathrm{N}$ suppliers the total (asymptotic) number of matches equals

$$
\mathrm{X}=\mathrm{Ng}{ }^{\mathrm{s}} \mathrm{m}=\mathrm{nm} \text {. }
$$

From (6.8) and (6.9) we therefore obtain that

$$
m=\left(\frac{\alpha X}{N-X}\right)^{1 / \theta_{1}}
$$

and

$$
\mathrm{n}=\left(\frac{\beta \mathrm{X}}{\mathrm{M}-\mathrm{X}}\right)^{1 / \theta_{2}}
$$

Let $\theta=\theta_{1}+\theta_{2}-\theta_{1} \theta_{2}$. Consequently, (6.10), (6.11) and (6.12) imply that $X$ must satisfy the equation

$$
\left(\frac{N-X}{\alpha}\right)^{\theta_{2} / \theta}\left(\frac{M-X}{\beta}\right)^{\theta_{1} / \theta}=X
$$

which generalizes (3.22). It is easily verified that eq. (6.13) has only one positive solution.

Let us next discuss a further modification of the distributional assumptions. Suppose now that $\alpha$ and $\beta$ are positive random variables. Then the analysis above becomes entirely similar and we obtain (6.6) and (6.7) where the expectation now is taken with respect to both $\alpha$ and $m^{\text {sd }}$ in (6.6) and $\beta$ and $n^{\text {ds }}$ in (6.7). The resulting asymptotic expressions are analogous to (6.8) and (6.9), and are given as

$$
n=N m^{\theta_{1}-1} E\left(\frac{1}{\alpha+m^{\theta_{1}}}\right)
$$


and

$$
m=M n^{\theta_{2}-1} E\left(\frac{1}{\beta+n^{\theta_{2}}}\right)
$$

where the expectation is taken with respect to $\alpha$ and $\beta$. The motivation for allowing $\alpha$ and $\beta$ to be random is that the population heterogeneity may be such that the distribution of the preferences cannot be represented by the extreme value distribution alone. It is easily verified that (6.14) and (6.15) have a unique solution for $\mathrm{n}$ and $\mathrm{m}$, and $\mathrm{X}=\mathrm{mn}$ is therefore uniquely determined as a function of $\theta_{1}, \theta_{2}$ and the distribution of $\alpha$ and $\beta$.

\subsection{The general case}

This subsection extends the framework developed in Section 5 so as to permit correlated tasteshifters as introduced above. Specifically, we assume that

$$
P\left(\bigcap_{d}\left(\varepsilon_{i j}^{s d}(w) \leq y_{d}\right)\right)=\exp \left(-\left(\sum_{d} y_{d}^{-1 / \theta_{1}}\right)^{\theta_{1}}\right)
$$

and

$$
P\left(\bigcap_{s}\left(\eta_{j i}^{d s}(w) \leq y_{s}\right)\right)=\exp \left(-\left(\sum_{s} y_{s}^{-1 / \theta_{2}}\right)^{\theta_{2}}\right)
$$

while $\varepsilon_{\mathrm{ij}}^{s d}(\mathrm{w})$ and $\varepsilon_{\mathrm{ab}}^{\tilde{s} \mathrm{~d}}(\tilde{\mathrm{w}})$ as well as $\eta_{\mathrm{ji}}^{\mathrm{ds}}(\mathrm{w})$ and $\eta_{\mathrm{ba}}^{\tilde{\mathrm{ds}}}(\tilde{\mathrm{w}})$ are assumed independent when $(s, a, b) \neq(\tilde{s}, i, j)$, and $(d, j, i) \neq(\tilde{d}, b, a)$, respectively. Similarly $\varepsilon_{i 0}^{s}$ and $\eta_{j 0}^{d}$ are independent of the other taste-shifters as well as independent across agents. The respective c.d.f. are the same as in (5.3). By a straight forward application of the Generalized Extreme Value model, cf. Ben-Akiva and Lerman (1985), p. 123, it follows readily that (5.14) to (5.17) extend to

$$
m_{i j}(w)=\frac{N_{i} b_{i j}(w) n_{j i}(w)^{\theta_{2}-1}}{\tilde{B}_{j}}
$$

and

$$
n_{j i}(w)=\frac{M_{j} a_{i j}(w) m_{i j}(w)^{\theta_{1}-1}}{\tilde{A}_{i}}
$$

where 


$$
\tilde{\mathrm{A}}_{\mathrm{i}}=\mathrm{a}_{\mathrm{i} 0}+\sum_{\mathrm{k}} \sum_{\mathrm{r}>0} \mathrm{a}_{\mathrm{ik}}(\mathrm{r}) \mathrm{m}_{\mathrm{ik}}(\mathrm{r})^{\theta_{1}}
$$

and

$$
\tilde{\mathrm{B}}_{\mathrm{j}}=\mathrm{b}_{\mathrm{j} 0}+\sum_{\mathrm{k}} \sum_{\mathrm{r}>0} \mathrm{~b}_{\mathrm{jk}}(\mathrm{r}) \mathrm{n}_{\mathrm{jk}}(\mathrm{r})^{\theta_{2}} .
$$

When (6.18) and (6.19) are combined we obtain

$$
m_{i j}(w)=\left[\frac{N_{i} b_{j i}(w)}{\widetilde{B}_{j}}\left(\frac{M_{j} a_{i j}(w)}{\tilde{A}_{i}}\right)^{\theta_{2}-1}\right]^{1 / \theta}
$$

and

$$
n_{j i}(w)=\left[\frac{M_{j} a_{i j}(w)}{\widetilde{A}_{i}}\left(\frac{N_{i} b_{j i}(w)}{\widetilde{B}_{j}}\right)^{\theta_{1}-1}\right]^{1 / \theta}
$$

where $\theta=\theta_{1}+\theta_{2}-\theta_{1} \theta_{2}$. Furthermore, (6.21) and (6.22) yield

$$
\begin{gathered}
X_{i j}(w)=m_{i j}(w) n_{j i}(w)=\left(\frac{N_{i} b_{j i}(w)}{\widetilde{B}_{j}}\right)^{\theta_{1} / \theta}\left(\frac{M_{j} a_{i j}(w)}{\tilde{A}_{i}}\right)^{\theta_{2} / \theta}, \\
X_{i 0}^{S}=\frac{a_{i 0} N_{i}}{\tilde{A}_{i}}
\end{gathered}
$$

and

$$
X_{j 0}^{D}=\frac{b_{j 0} M_{j}}{\tilde{B}_{j}},
$$

which extend the model derived in Section 5.

\section{Theorem 2}

Suppose $a_{i 0}>0$ and $b_{j 0}>0$ for all $i$ and $j$. Then the equations (6.20) to (6.23) determine $\left\{m_{i j}(w)\right\}$ and $\left\{n_{j i}(w)\right\}$ uniquely.

The proof of Theorem 2 is given in the appendix. 


\section{Complements}

In this section we collect some complements and remarks that have relevance for potential applications.

7.1 Note that by (5.16) we can express (5.18) as

$$
q_{i j}^{s}(w)=\frac{a_{i j}(w) m_{i j}(w)}{a_{i 0}+\sum_{k} \sum_{r>0} a_{i k}(r) m_{i k}(r)}
$$

Suppose now that the demands $\left\{\mathrm{m}_{\mathrm{ij}}(\mathrm{w})\right\}$ are observable. Then (7.1) suggests a convenient way of estimating the preference terms $\left\{a_{i j}(w)\right\}$ from microdata on realized choices in a matching market. Specifically, if $\mathrm{v}_{\mathrm{ij}}(w)=\log _{\mathrm{ij}}(\mathrm{w})$ is specified as a parametric function in explanatory variables, then the preference structure can be estimated by a multinominal logit type of analysis in which the structural terms $v_{\mathrm{ij}}(w)$ must be adjusted by adding $\log \mathrm{m}_{\mathrm{ij}}(w)$.

7.2 Suppose now that $\left\{\mathrm{m}_{\mathrm{ij}}(\mathrm{w})\right\}$ are not observable but that precise estimates on the number of demanders that are selfmatched, $X_{j 0}^{D}$, are available. With $b_{j 0}=1,(5.25)$ yields

$$
X_{j 0}^{\mathrm{D}}=\frac{M_{j}}{B_{j}}
$$

which by (5.21) and (5.20) imply that

$$
q_{i j}^{s}(w)=\frac{a_{i j}(w) b_{j i}(w) X_{j 0}^{D}}{a_{i 0}+\sum_{k} \sum_{r>0} a_{i k}(r) b_{k i}(r) X_{k 0}^{D}}
$$

If a parametric specification of $\log \mathrm{a}_{\mathrm{ij}}(w)+\log \mathrm{b}_{\mathrm{ji}}(w)$ is chosen the model can, as above, be estimated by a multinomial logit type of analysis on microdata in which the structural terms must be adjusted by the logarithm of the numbers of self-matched demanders of the respective types.

\section{Simulation experiments}

Recall that the models derived above are only assumed to hold asymptotically, i.e., when the respective population groups are large. It is therefore of considerable interest to analyze how the different model versions perform in small population groups. To this end, we report results from a few 
selected simulation experiments. For more detailed simulation results we refer to Dagsvik and Johansen (1996). The simulation experiments are carried out as follows: First independent tasteshifters are drawn from the extreme value distribution (3.3). From these draws and selected values of the systematic terms of the agents' utility functions, preference lists are assigned to every agent. Subsequently, the deferred acceptance algorithm is simulated, which produces the matchings. Tables 1 and 2 below display the results. In Table 1 we report the results from simulating the model discussed in Section 3. We have performed simulations with 14 different sets of population sizes and preference parameters. For each set of parameters the experiments were replicated 1000 times to obtain precise estimates of the respective means and standard deviations.

Table 1. Simulation results with observationally suppliers and demanders

\begin{tabular}{|c|c|c|c|c|c|c|c|}
\hline & \multicolumn{2}{|c|}{ Preferences } & \multicolumn{2}{|c|}{ Population size } & \multicolumn{3}{|c|}{ Number of matches } \\
\hline & $\alpha$ & $\beta$ & $\mathrm{N}$ & $\mathbf{M}$ & Predicted & Simulated & $\begin{array}{l}\text { Standard } \\
\text { deviation }\end{array}$ \\
\hline 1 & 7 & 7 & 50 & 50 & 19.27 & 17.73 & 2.97 \\
\hline 2 & 7 & 10 & 50 & 150 & 31.44 & 30.05 & 3.29 \\
\hline 3 & 1 & 2 & 60 & 80 & 55.48 & 54.56 & 2.01 \\
\hline 4 & 1 & 1 & 30 & 15 & 14.11 & 13.58 & 1.10 \\
\hline 5 & 4 & 1 & 30 & 20 & 15.64 & 14.67 & 1.74 \\
\hline 6 & 6 & 8 & 15 & 20 & 3.79 & 3.32 & 1.54 \\
\hline 7 & 9 & 3 & 10 & 15 & 3.07 & 2.57 & 1.27 \\
\hline 8 & 20 & 1 & 15 & 90 & 11.94 & 10.05 & 1.78 \\
\hline 9 & 3 & 4 & 20 & 40 & 13.73 & 12.72 & 1.98 \\
\hline 10 & 2 & 1 & 10 & 5 & 3.78 & 3.32 & 1.01 \\
\hline 11 & 1 & 5 & 80 & 40 & 35.92 & 33.78 & 2.10 \\
\hline 12 & 30 & 7 & 30 & 70 & 6.93 & 6.25 & 2.03 \\
\hline 13 & 3 & 2 & 20 & 20 & 11.64 & 10.57 & 1.85 \\
\hline 14 & 2 & 5 & 8 & 15 & 4.16 & 3.57 & 1.29 \\
\hline
\end{tabular}

The fifth column in Table 1 displays the predicted number of matches that follows from (3.23). In coloumns 6 and 7 we report the mean of the number of simulated matches (across the 1000 replications) and the standard deviation of the number of matches. The table shows that the model provides excellent predictions.

In Table 2 we report the results from a more general experiment in which there are two observed types of suppliers and demanders. We report the results from four experiments where each type of experiment is replicated 100 times. 
Table 2. Simulation results with two types of suppliers and demanders

\begin{tabular}{|c|c|c|c|c|c|c|}
\hline Experiments & & & 1 & 2 & 3 & 4 \\
\hline Preferences & & $\begin{array}{l}a_{11} \\
a_{12} \\
a_{21} \\
a_{22} \\
b_{11} \\
b_{12} \\
b_{21} \\
b_{22}\end{array}$ & $\begin{array}{l}8 \\
2 \\
3 \\
2 \\
1 \\
1 \\
2 \\
3 \\
\end{array}$ & $\begin{array}{c}20 \\
3 \\
8 \\
1 \\
5 \\
2 \\
3 \\
1 \\
\end{array}$ & $\begin{array}{c}1 \\
0.2 \\
0.2 \\
2 \\
8 \\
1 \\
1 \\
3 \\
\end{array}$ & $\begin{array}{c}4 \\
0.5 \\
3 \\
2 \\
1 \\
1 \\
1 \\
2 \\
-\end{array}$ \\
\hline $\begin{array}{l}\text { Population } \\
\text { sizes }\end{array}$ & & $\begin{array}{l}\mathrm{N}_{1} \\
\mathrm{~N}_{2} \\
\mathrm{M}_{1} \\
\mathrm{M}_{2}\end{array}$ & $\begin{array}{r}20 \\
15 \\
30 \\
8\end{array}$ & $\begin{array}{r}30 \\
10 \\
5 \\
20\end{array}$ & $\begin{array}{l}20 \\
60 \\
10 \\
30\end{array}$ & $\begin{array}{l}15 \\
20 \\
10 \\
15\end{array}$ \\
\hline $\begin{array}{l}\text { Mean number } \\
\text { of matches }\end{array}$ & $\begin{array}{l}\text { Predicted } \\
\text { Simulated } \\
\text { Predicted } \\
\text { Simulated } \\
\text { Predicted } \\
\text { Simulated } \\
\text { Predicted } \\
\text { Simulated }\end{array}$ & $\begin{array}{l}X_{11} \\
X_{11} \\
X_{12} \\
X_{12} \\
X_{21} \\
X_{21} \\
X_{22} \\
X_{22}\end{array}$ & $\begin{array}{c}17.16 \\
17.03 \\
2.24 \\
2.45 \\
9.29 \\
9.84 \\
4.84 \\
4.26 \\
\end{array}$ & $\begin{array}{r}4.33 \\
4.88 \\
17.85 \\
16.72 \\
0.66 \\
0.12 \\
1.89 \\
2.35 \\
-1 .\end{array}$ & $\begin{array}{r}9.23 \\
8.51 \\
0.34 \\
0.49 \\
0.66 \\
1.25 \\
29.49 \\
29.21 \\
\end{array}$ & $\begin{array}{r}6.40 \\
6.68 \\
2.17 \\
1.88 \\
3.35 \\
3.07 \\
12.15 \\
12.34 \\
\end{array}$ \\
\hline $\begin{array}{l}\text { Standard } \\
\text { deviations }\end{array}$ & & $\begin{array}{l}s_{11} \\
s_{12} \\
s_{21} \\
s_{22}\end{array}$ & $\begin{array}{l}1.41 \\
1.24 \\
1.19 \\
1.21\end{array}$ & $\begin{array}{l}0.32 \\
1.23 \\
0.32 \\
0.97\end{array}$ & $\begin{array}{l}1.65 \\
0.83 \\
1.43 \\
0.94\end{array}$ & $\begin{array}{l}1.04 \\
0.72 \\
1.00 \\
0.93\end{array}$ \\
\hline
\end{tabular}

The predictions reported in Table 2 are obtained from (5.20), (5.21) and (5.22) with the number of feasible contracts equal to one and with $a_{i 0}=b_{j 0}=1$. Thus the (mean) number of matches predicted, where the supplier is of type $i$ and the demander is of type $j$, equals

$$
X_{i j}=\frac{N_{i} M_{j} a_{i j} b_{j i}}{A_{i} B_{j}}
$$

where $A_{i}$ and $B_{j}$ are determined by

$$
A_{i}=1+\sum_{k=1}^{2} a_{i k} b_{k i} M_{k} / B_{k}
$$

and

$$
\mathrm{B}_{\mathrm{j}}=1+\sum_{\mathrm{k}=1}^{2} \mathrm{a}_{\mathrm{kj}} \mathrm{b}_{\mathrm{jk}} \mathrm{N}_{\mathrm{k}} / \mathrm{A}_{\mathrm{k}}
$$

for $i, j=1,2$. 
Similarly to the results reported in Table 1, the results displayed in Table 2 also demonstrate that there is practically no bias in the theoretical predictions from the model.

\section{Conclusion}

In this paper we have discussed the problem of aggregation in particular matching markets.

Under specific assumptions about the matching game and the distribution of the agents preferences we have obtained tractable expressions for key aggregate relations, such as the number of realized matches. We have discussed the deferred acceptance algorithm as a possible behavioral story that yield stable matchings. This algorithm has been extended to allow for a finite menu of flexible contracts, such as a price - or a wage rate. This is of interest in many fields of application, such as the labor market and the market for education.

Since the aggregate relations are asymptotic ones we have conducted a series of simulation experiments to assess the degree of bias in small populations. The simulation experiments indicate that the prediction bias in small populations is negligible. 


\section{Appendix}

\section{Proof of Lemma 1}

Note first that the moment generating function of $\mathrm{I}^{\mathrm{sk}}$ conditional on $\mathrm{n}^{\mathrm{ks}}$, equals

$$
E\left(z^{\mathrm{s}^{\mathrm{sk}}} \mid \mathrm{n}^{\mathrm{ks}}\right)=1-\hat{\mathrm{g}}^{\mathrm{D}}\left(\mathrm{n}^{\mathrm{ks}}\right)+\mathrm{z} \hat{\mathrm{g}}^{\mathrm{D}}\left(\mathrm{n}^{\mathrm{ks}}\right)
$$

Since $\mathrm{I}^{\mathrm{sk}}, \mathrm{k}=1,2, \ldots$, are independent when $\mathrm{n}^{\mathrm{ks}}$ are given we get

$$
\mathrm{E}\left(\mathrm{z}^{\mathrm{m}^{\mathrm{sd}}}\right)=\underset{\mathrm{k} \neq \mathrm{d}}{\mathrm{E}}\left(\mathrm{z}^{\mathrm{I}^{\mathrm{s}}} \mid \mathrm{n}^{\mathrm{ks}}\right)=\underset{\mathrm{k} \neq \mathrm{d}}{\mathrm{E}}\left(1-\hat{\mathrm{g}}^{\mathrm{D}}\left(\mathrm{n}^{\mathrm{ks}}\right)+\mathrm{z} \hat{\mathrm{g}}^{\mathrm{D}}\left(\mathrm{n}^{\mathrm{ks}}\right)\right)
$$

for $\mathrm{z} \in[0,1]$, where

$$
\hat{\mathrm{g}}^{\mathrm{D}}(\mathrm{n})=\frac{1}{1+\beta+\mathrm{n}}
$$

If $\mathrm{X}$ is a non-negative discrete random variable it is immediately veryfied that

$$
E\left(\frac{1}{1+\tau+X}\right)=\int_{0}^{1} z^{\tau-1} E\left(z^{X}\right) d z
$$

for any positive constant $\tau$. Consequently, (A.2) and (A.4) imply that

$$
E\left(\frac{1}{1+\tau+m^{s d}}\right)=E\left(\int_{0}^{1} z^{\tau} \prod_{k \neq d}\left(1-\hat{g}^{D}\left(n^{k s}\right)+z \hat{g}^{D}\left(n^{k s}\right)\right) d z\right) .
$$

Observe next that $e^{z-1}-z \geq 0$ when $z \in[0,1]$. To realize this we note that $e^{z-1}-z$ is decreasing in $z$ and consequently i's minimum value is zero and it is attained at $z=1$. Therefore

$$
\begin{aligned}
& \int_{0}^{1} z^{\tau} \prod_{k \neq d}\left(1-\hat{g}^{D}\left(n^{k s}\right)+z \hat{g}^{D}\left(n^{k s}\right)\right) d z \leq \int_{0}^{1} \exp \left(\tau(z-1)+(z-1) \sum_{k \neq d} \hat{g}^{D}\left(n^{k s}\right)\right) d s \\
& =\frac{1-\exp \left(-\tau-\sum_{k \neq d} \hat{g}^{D}\left(n^{k s}\right)\right)}{\tau+\sum_{k \neq d} \hat{g}^{D}\left(n^{k s}\right)} \leq f_{d}\left(n^{1 s}, n^{2 s}, \ldots, n^{M s}\right)
\end{aligned}
$$

where

$$
\mathrm{f}_{\mathrm{d}}\left(\mathrm{n}^{1 \mathrm{~s}}, \mathrm{n}^{2 \mathrm{~s}}, \ldots, \mathrm{n}^{\mathrm{Ms}}\right)=\frac{1}{\tau+\sum_{\mathrm{k} \neq \mathrm{d}} \frac{1}{1+\beta+\mathrm{n}^{\mathrm{ks}}}}
$$


From (3.6) and (3.7) it follows that

$$
E\left(m^{s d}\right)=\sum_{k \neq d} E\left(I^{s k} \mid s \in A^{k}\right)=(M-1) g^{D}
$$

and

$$
E\left(n^{d s}\right)=\sum_{k \neq d} E\left(I^{d k} \mid d \in B^{k}\right)=(N-1) g^{s}
$$

Since the function $\mathrm{f}$ is concave in $\left(\mathrm{n}^{1 \mathrm{~s}}, \mathrm{n}^{2 \mathrm{~s}}, \ldots\right)$ on $\mathrm{R}_{+}^{\mathrm{M}-1}$, it follows from Jensen's inequality, (A.5) and (A.9) that

$$
\begin{aligned}
& E\left(\frac{1}{1+\tau+m^{s d}}\right) \leq \operatorname{Ef}_{d}\left(n^{1 s}, n^{2 s}, \ldots, n^{M s}\right) \\
& \leq f_{d}\left(\operatorname{En}^{1 s}, \operatorname{En}^{2 s}, \ldots, \operatorname{En}^{M s}\right)=\frac{1}{\tau+\frac{M-1}{1+\beta+(N-1) g^{s}}} .
\end{aligned}
$$

which proves the right hand side of (3.14). The left hand side of (3.14) follows directly by the application of Jensen's inequality and inserting for $E\left(\mathrm{~m}^{\text {sd }}\right)$ given by (A.8). The proof of (3.15) is completely analogous.

Q.E.D.

\section{Proof of Theorem 1:}

Put $\tau_{1}=\alpha$ and $\tau_{2}=\beta$ in (3.14) and (3.15). When $N$ and $M$ are large Lemma 1 implies that for

$$
\frac{\psi}{\bar{\alpha}+u} \leq v \leq \frac{\psi}{\bar{\alpha}+\frac{\psi^{-1}}{\bar{\beta}+v}}
$$

and

$$
\frac{\psi^{-1}}{\bar{\beta}+v} \leq u \leq \frac{\psi^{-1}}{\bar{\beta}+\frac{\psi}{\bar{\alpha}+u}}
$$

By inverting the right hand side of (A.11) we get

$$
\frac{\Psi}{v} \geq \bar{\alpha}+\frac{\psi^{-1}}{\bar{\beta}+v}
$$

and similarly from (A.12) we get 


$$
\frac{\Psi^{-1}}{\mathrm{u}} \geq \bar{\beta}+\frac{\psi}{\bar{\alpha}+\mathrm{u}}
$$

By multiplying (A.13) by $v$ and (A.14) by $u$ we obtian that

$$
\psi+\frac{\bar{\beta} \psi^{-1}}{\bar{\beta}+\mathrm{v}} \geq \bar{\alpha} \mathrm{v}+\psi^{-1}
$$

and

$$
\psi^{-1}+\frac{\bar{\alpha} \psi}{\bar{\alpha}+u} \geq \bar{\beta} u+\psi
$$

Let

$$
x=\psi^{-1}+\frac{\bar{\alpha} \psi}{\bar{\alpha}+u}-\bar{\beta} u-\psi
$$

and

$$
y=\psi+\frac{\bar{\beta} \psi^{-1}}{\bar{\beta}+v}-\bar{\alpha} v-\psi^{-1}
$$

From (A.12) and (A.11) we have that

$$
\frac{\bar{\alpha} \psi}{\bar{\alpha}+u} \leq \bar{\alpha} v \text { and } \frac{\bar{\beta} \psi^{-1}}{\bar{\beta}+v} \leq \bar{\beta} u
$$

which imply that

$$
x \leq \psi^{-1}+\bar{\alpha} v-\bar{\beta} u-\psi
$$

and

$$
\mathrm{y} \leq \psi+\bar{\beta} \mathrm{u}-\bar{\alpha} \mathrm{v}-\psi^{-1} .
$$

But (A.19) and (A.20) imply that $x+y \leq 0$. Since by (A.15) and (A.16), $x \geq 0$ and $y \geq 0$, we conclude that $x=y=0$. Consequently, the inequalities on the right hand sides of (A.11) and (A.12) reduce to equalities, i.e.,

$$
v=\frac{\psi}{\bar{\alpha}+\frac{\psi^{-1}}{\bar{\beta}+v}}
$$

and 


$$
u=\frac{\psi^{-1}}{\bar{\beta}+\frac{\psi}{\bar{\alpha}+u}}
$$

When (3.16) is inserted into (3.17) and (3.17) is inserted into (3.16), respectively, we obtain (A.22) and (A.21). It is straight forward to show that (A.21) and (A.22) have only one positive solution.

It now only remains to prove that $\mathrm{m}^{\text {sd }} / \sqrt{\mathrm{M}}$ and $\mathrm{n}^{\mathrm{ds}} / \sqrt{\mathrm{N}}$ converge in probability toward $\mathrm{u}$ and $v$, respectively. From (3.14), (3.16) and (3.17) we get with $\tau=\tau_{1} \sqrt{\mathrm{M}}$

$$
\frac{1}{\tau+u} \leq \lim _{M \rightarrow \infty} E\left(\frac{1}{\tau+m^{s d} / \sqrt{M}}\right) \leq \frac{1}{\tau+\frac{\psi^{-1}}{\bar{\beta}+v}}
$$

But by (3.17) the right hand side of (A.23) equals $(\tau+u)^{-1}$ which by (A.23) implies that

$$
\lim _{M \rightarrow \infty} E\left(\frac{1}{\tau+m^{s d} / \sqrt{M}}\right)=\frac{1}{\tau+u}
$$

for any positive $\tau$. The left hand side of (A.24) is the Stieltjes transform of the c.d.f. of $\mathrm{m}^{\mathrm{sd}} / \sqrt{\mathrm{M}}$ (see Widder, 1941) which has the same uniqueness and convergence properties as the Laplace transform. Thus since the right hand side of (A.24) is the Stieltjes transform of a degenerate distribution it follows that

$$
\mathrm{m}^{\mathrm{sd}} / \sqrt{\mathrm{M}} \stackrel{\mathrm{p}}{\longrightarrow} \mathrm{u}
$$

The proof that

$$
\mathrm{n}^{\mathrm{ds}} / \sqrt{\mathrm{N}} \stackrel{\mathrm{p}}{\longrightarrow} \mathrm{v}
$$

is completely analogous to the proof above.

Q.E.D.

\section{Proof of Theorem 2:}

Let $F=\left(F^{\prime}, F^{\prime \prime}\right)$, where $F^{\prime}$ and $F^{\prime \prime}$ are mappings $F^{\prime}, F^{\prime \prime}: R^{2 S D W} \rightarrow R^{2 S D W}$. The components of $F^{\prime}$ are given by 


$$
\begin{aligned}
\mathrm{F}_{\mathrm{ijw}}^{\prime}(\mathrm{x}, \mathrm{y}) & =\log \left[\left(\mathrm{N}_{\mathrm{i}} \mathrm{b}_{\mathrm{ji}}(\mathrm{w})\right)^{1 / \theta}\left(\mathrm{M}_{\mathrm{j}} \mathrm{a}_{\mathrm{ij}}(\mathrm{w})\right)^{\left(\theta_{2}-1\right) / \theta}\right] \\
& -\frac{1}{\theta} \log \left(\mathrm{b}_{\mathrm{j} 0}+\sum_{\mathrm{k}} \sum_{\mathrm{r}>0} \mathrm{~b}_{\mathrm{jk}}(\mathrm{r}) \exp \left(\theta_{2} \mathrm{y}_{\mathrm{jk}}(\mathrm{r})\right)\right) \\
& +\frac{\left(1-\theta_{2}\right)}{\theta} \log \left(\mathrm{a}_{\mathrm{i} 0}+\sum_{\mathrm{k}} \sum_{\mathrm{r}>0} \mathrm{a}_{\mathrm{ik}}(\mathrm{r}) \exp \left(\theta_{1} \mathrm{x}_{\mathrm{ik}}(\mathrm{r})\right)\right)
\end{aligned}
$$

and the components of $F^{\prime \prime}$ are given by

$$
\begin{aligned}
F_{j i w}^{\prime \prime}(x, y)= & \log \left[\left(M_{j} a_{i j}(w)\right)^{1 / \theta}\left(N_{i} b_{j i}(w)\right)^{\left(\theta_{1}-1\right) / \theta}\right] \\
& -\frac{1}{\theta} \log \left(a_{i 0}+\sum_{k} \sum_{r>0} a_{i k}(r) \exp \left(\theta_{1} x_{i k}(r)\right)\right) \\
& +\frac{\left(1-\theta_{1}\right)}{\theta} \log \left(b_{j 0}+\sum_{k} \sum_{r>0} b_{j k}(r) \exp \left(\theta_{2} y_{j k}(r)\right)\right)
\end{aligned}
$$

We realize that (A.25) and (A.26) equal the logarithm of the right hand side of (6.22) and (6.23) with $x_{i j}(w)=\log m_{i j}(w)$ and $y_{j i}(w)=\log n_{j i}(w)$. Note that there is no loss of generality in assuming that $\mathrm{x} \equiv\left\{\mathrm{x}_{\mathrm{ij}}(\mathrm{w})\right\}$ and $\mathrm{y} \equiv\left\{\mathrm{y}_{\mathrm{ji}}(\mathrm{w})\right\}$ are restricted to a compact set, $\Lambda$ (say). To realize this, note that by (6.20) and (6.21)

$$
a_{i 0} \leq \tilde{A}_{i} \leq \sum_{k} \sum_{r>0} a_{i k}(r) M_{k}
$$

and

$$
b_{j 0} \leq \tilde{B}_{j} \leq \sum_{k} \sum_{r>0} b_{j k}(r) N_{k}
$$

which, by (6.22) and (6.23), imply that $m_{\mathrm{ij}}(w)$ and $n_{\mathrm{ji}}(w)$ are bounded from above and bounded away from zero. Hence, $x$ and $y$ can be restricted to a compact set. We have

$$
\frac{\partial F_{i j w}^{\prime}(x, y)}{\partial x_{i k}(r)}=\frac{\left(1-\theta_{2}\right) \theta_{1} a_{i k}(r) \exp \left(\theta_{1} x_{i k}(r)\right)}{\theta \tilde{A}_{i}}
$$

and

$$
\frac{\partial F_{i j w}^{\prime}(x, y)}{\partial y_{j k}(r)}=-\frac{\theta_{2} b_{j k}(r) \exp \left(\theta_{2} y_{j k}(r)\right)}{\theta \widetilde{B}_{j}}
$$

Let 


$$
K=\max _{i, j}\left(1-\frac{a_{i 0}}{\tilde{A}_{i}}, 1-\frac{b_{j 0}}{\widetilde{B}_{j}}\right)
$$

Since $\tilde{\mathrm{A}}_{\mathrm{i}}$ and $\tilde{\mathrm{B}}_{\mathrm{j}}$ are bounded and positive, $\mathrm{K}$ must be less than one. Hence, (A.29) and (A.30) imply that

$$
\begin{aligned}
& \sum_{\mathrm{k}} \sum_{\mathrm{r}>0}\left(\left|\frac{\partial \mathrm{F}_{\mathrm{ijw}}^{\prime}(\mathrm{x}, \mathrm{y})}{\partial \mathrm{x}_{\mathrm{ik}}(\mathrm{r})}\right|+\left|\frac{\partial \mathrm{F}_{\mathrm{ijw}}^{\prime}(\mathrm{x}, \mathrm{y})}{\partial \mathrm{y}_{\mathrm{jk}}(\mathrm{r})}\right|\right) \\
& \leq \frac{\left(1-\theta_{2}\right) \theta_{1}\left(\tilde{\mathrm{A}}_{\mathrm{i}}-\mathrm{a}_{\mathrm{i} 0}\right)}{\theta \tilde{\mathrm{A}}_{\mathrm{i}}}+\frac{\theta_{2}\left(\tilde{\mathrm{B}}_{\mathrm{j}}-\mathrm{b}_{\mathrm{j} 0}\right)}{\theta \tilde{\mathrm{B}}_{\mathrm{j}}} \leq \frac{\left(\theta_{1}-\theta_{1} \theta_{2}+\theta_{2}\right) \mathrm{K}}{\theta}=\mathrm{K}<1 .
\end{aligned}
$$

Similarly, it follows that

$$
\sum_{\mathrm{k}} \sum_{\mathrm{r}>0}\left(\left|\frac{\partial \mathrm{F}_{\mathrm{jiw}}^{\prime \prime}(\mathrm{x}, \mathrm{y})}{\partial \mathrm{x}_{\mathrm{ik}}(\mathrm{r})}\right|+\left|\frac{\partial \mathrm{F}_{\mathrm{jiw}}^{\prime \prime}(\mathrm{x}, \mathrm{y})}{\partial \mathrm{y}_{\mathrm{jk}}(\mathrm{r})}\right|\right) \leq \mathrm{K}<1
$$

Let \|\| be the norm defined by $\|x\|=\max _{k}\left|x_{k}\right|$, for $x \in R^{2 S D W}$. Now by the mean value theorem for vector fields we have

$$
\mathrm{F}_{\mathrm{ijw}}^{\prime}\left(\mathrm{x}^{\prime}, \mathrm{y}^{\prime}\right)-\mathrm{F}_{\mathrm{ijw}}^{\prime}(\mathrm{x}, \mathrm{y})=\sum_{\mathrm{k}} \sum_{\mathrm{r}>0}\left(\frac{\partial \mathrm{F}_{\mathrm{ijw}}^{\prime}\left(\mathrm{x}^{*}, \mathrm{y}^{*}\right)}{\partial \mathrm{y}_{\mathrm{jkr}}}\left(\mathrm{y}_{\mathrm{j} \mathrm{kr}}^{\prime}-\mathrm{y}_{\mathrm{jkr}}\right)+\frac{\partial \mathrm{F}_{\mathrm{ijw}}^{\prime}\left(\mathrm{x}^{*}, \mathrm{y}^{*}\right)}{\partial \mathrm{x}_{\mathrm{ikr}}}\left(\mathrm{x}_{\mathrm{ikr}}^{\prime}-\mathrm{x}_{\mathrm{ikr}}\right)\right)
$$

and

$$
F_{j i w}^{\prime \prime}\left(x^{\prime}, y^{\prime}\right)-F_{j i w}^{\prime \prime}(x, y)=\sum_{k} \sum_{r>0}\left(\frac{\partial F_{j i w}^{\prime \prime}\left(x^{*}, y^{*}\right)}{\partial x_{i k r}}\left(x_{i k r}^{\prime}-x_{i k r}\right)+\frac{\partial F_{j i w}^{\prime \prime}\left(x^{*}, y^{*}\right)}{\partial y_{j k r}}\left(y_{j k r}^{\prime}-y_{j k r}\right)\right)(A
$$

where $\left(\mathrm{x}^{\prime}, \mathrm{y}^{\prime}\right)$ and $(\mathrm{x}, \mathrm{y})$ are two elements in $\mathrm{R}^{2 \mathrm{SDw}}$ and $\left(\mathrm{x}^{*}, \mathrm{y}^{*}\right)$ is a point on the hyperplan through $\left(\mathrm{x}^{\prime}, \mathrm{y}^{\prime}\right)$ and (x,y). From (A.31), (A32), (A.33) and (A.34) we get

$$
\left|F_{i j w}^{\prime}\left(x^{\prime}, y^{\prime}\right)-F_{i j w}^{\prime}(x, y)\right| \leq K \max _{k, r>0}\left|y_{j k r}^{\prime}-y_{j k r}\right|+K \max _{k, r>0}\left|x_{i k r}^{\prime}-x_{i k r}\right|
$$

and

$$
\left|F_{j i w}^{\prime \prime}\left(x^{\prime}, y^{\prime}\right)-F_{j i w}^{\prime \prime}(x, y)\right| \leq K \max _{k, r>0}\left|x_{i k r}-x_{i k r}\right|+K \max _{k, r>0}\left|y_{j k r}^{\prime}-y_{j k r}\right|
$$

which imply that

$$
\left\|F\left(x^{\prime}, y^{\prime}\right)-F(x, y)\right\| \leq K\left\|\left(x^{\prime}, y^{\prime}\right)-(x, y)\right\| .
$$


Consequently, $\mathrm{F}$ is a contraction mapping. From Blackwell's Theorem (Blackwell, 1965) we then know that the equation

$$
(x, y)=F(x, y)
$$

has a unique fixed point in $\Lambda$.

Q.E.D. 


\section{References}

Becker, G.S. (1981): A Treatise on the Family. Harvard University Press, Cambridge.

Ben-Akiva, M. and S.R. Lerman (1985): Discrete Choice Analysis. MIT Press, Cambridge.

Blackwell, D. (1965): Discounted Dynamic Programming. Annals of Mathematical Statistics, 36, 226235.

Burdett, K. and T. Vishwanath (1988): Balanced Matching Equilibrium. Journal of Political Economy, 96, 1048-1065.

Burdett, K. and D. Mortensen (1988): Equilibrium Wage Distributions. Mimeo.

Crawford, V.P. and E.M. Knoer (1981): Job Matching with Heterogeneous Firms and Workers. Econometrica, 49, 437-450.

Chung, R. (1994): Cycles in the Two-Sex Problem: An Investigation of a Nonlinear Demographic Model. Mathematical Population Studies, 5, 45-73.

Dagsvik, J.K. (1993): Choice Probabilities and Equilibrium Conditions in a Matching Market with Flexible Contracts. Discussion Paper no. 94, Statistics Norway, Oslo.

Dagsvik, J.K. and R. Johansen (1996): A Behavioral Marriage Function. (Forthcoming).

Diamond, P. and E. Maskin (1979): An Equilibrium Analysis of Search and Breach of Contract, I: Steady States. Bell Journal of Economics, 10, 282-316.

Diamond, P. and E. Maskin (1982): An Equilibrium Analysis of Search and Breach of Contract, II: A non-Steady State Example. Journal of Economic Theory, 25, 165-195.

Eriksen, E.A. (1986): Generalized Extreme Value Discrete Choice Demand Models. Regional Science and Urban Economics, 16, 547-572.

Gale, D. and L. Shapley (1962): College Admissions and the Stability of Marriage. American Mathematical Monthly, 69, 9-15.

Hoem, J.M. (1969): Concepts of a Bisexual Theory of Marriage Formation. Statistisk Tidsskrift, 4, 295-300.

Lemesurier, P. (1977): The Great Pyramide Decoded. Element Books, Ltd., Longmead, Shaftesbury, Dorset, Great Britain.

McFarland, D.D. (1972): Comparison of Alternative Marriage Models. In T.N.E. Greville (eds.); Population Dynamics. Academic Press, New York.

Mortensen, D. (1982): The Matching Process as a Noncooperative Bargaining Game. In J. McCall (eds.); The Economics of Information and Uncertainty, University of Chicago Press, Chicago.

Mortensen, D. (1988): Matching: Finding a Partner for Life or Otherwise. The American Journal of Sociology, 94, S215-S240.

Pollak, R.A. (1990): Two-Sex Demographic Models. Journal of Political Economy, 98, 399-420. 
Pollard, J.H. (1977): The Continuing Attempt to Incorporate Both Sexes into Marriage Analysis. International Population Conference, 1, 291-308, Mexico.

Roth, A.E. and M.A.O. Sotomayor (1990): Two-sided Matching. Cambridge University Press, New York.

Schoen, R. (1977) A Two-sex Nuptiality-Mortality Life Table. Demography, 14, 333-347.

Schwaller de Lubicz, R.A. (1985): The Egyptian Miracle. Inner Tradition International, Ltd., New York.

Shapley, L. and M. Shubik (1972): The Assignment Game I: The Core. International Journal of Game Theory, 1, 110-130.

Tinbergen, J. (1956): On the Theory of Income Distribution. Weltwirtschaftliches Archiv, 77, 155-175.

Widder, D.V. (1941): The Laplace Transform. Princeton University Press, New Jersey. 


\section{Issued in the series Discussion Papers}

42 R. Aaberge, Ø. Kravdal and T. Wennemo (1989): Unobserved Heterogeneity in Models of Marriage Dissolution.

K.A. Mork, H.T. Mysen and Ø. Olsen (1989): Business Cycles and Oil Price Fluctuations: Some evidence for six OECD countries.

B. Bye, T. Bye and L. Lorentsen (1989): SIMEN. Studies of Industry, Environment and Energy towards 2000.

\section{O. Bjerkholt, E. Gjelsvik and $\varnothing$. Olsen (1989): Gas} Trade and Demand in Northwest Europe: Regulation, Bargaining and Competition.

\section{L.S. Stambøl and K. $\varnothing$. Sørensen (1989): Migration} Analysis and Regional Population Projections.

V. Christiansen (1990): A Note on the Short Run Versus Long Run Welfare Gain from a Tax Reform.

S. Glomsrød, H. Vennemo and T. Johnsen (1990): Stabilization of Emissions of $\mathrm{CO}_{2}$ : A Computable General Equilibrium Assessment.

J. Aasness (1990): Properties of Demand Functions for Linear Consumption Aggregates.

\section{J.G. de Leon (1990): Empirical EDA Models to Fit and} Project Time Series of Age-Specific Mortality Rates.

J.G. de Leon (1990): Recent Developments in Parity Progression Intensities in Norway. An Analysis Based on Population Register Data

R. Aaberge and T. Wennemo (1990): Non-Stationary Inflow and Duration of Unemployment

\section{R. Aaberge, J.K. Dagsvik and S. Strøm (1990): Labor} Supply, Income Distribution and Excess Burden of Personal Income Taxation in Sweden

\section{R. Aaberge, J.K. Dagsvik and S. Strøm (1990): Labor} Supply, Income Distribution and Excess Burden of Personal Income Taxation in Norway

H. Vennemo (1990): Optimal Taxation in Applied General Equilibrium Models Adopting the Armington Assumption

N.M. Stølen (1990): Is there a NAIRU in Norway?

A. Cappelen (1991): Macroeconomic Modelling: The Norwegian Experience

J.K. Dagsvik and R. Aaberge (1991): Household Production, Consumption and Time Allocation in Peru

R. Aaberge and J.K. Dagsvik (1991): Inequality in Distribution of Hours of Work and Consumption in Peru

T.J. Klette (1991): On the Importance of R\&D and Ownership for Productivity Growth. Evidence from Norwegian Micro-Data 1976-85

1 K.H. Alfsen (1991): Use of Macroeconomic Models in Analysis of Environmental Problems in Norway and Consequences for Environmental Statistics

H. Vennemo (1991): An Applied General Equilibrium Assessment of the Marginal Cost of Public Funds in Norway

H. Vennemo (1991): The Marginal Cost of Public Funds: A Comment on the Literature

A. Brendemoen and H. Vennemo (1991): A climate convention and the Norwegian economy: A CGE assessment

K.A. Brekke (1991): Net National Product as a Welfare

Indicator

E. Bowitz and E. Storm (1991): Will Restrictive Demand Policy Improve Public Sector Balance?

Å. Cappelen (1991): MODAG. A Medium Term Macroeconomic Model of the Norwegian Economy

\section{B. Bye (1992): Modelling Consumers' Energy Demand} Benefits of Climate Policies: Some Tentative Calculations

R. Aaberge, Xiaojie Chen, Jing $\mathrm{Li}$ and Xuezeng $\mathrm{Li}$ (1992): The Structure of Economic Inequality among Households Living in Urban Sichuan and Liaoning, 1990

K.H. Alfsen, K.A. Brekke, F. Brunvoll, H. Lurås, K. Nyborg and H.W. Sæbø (1992): Environmental Indicators

B. Bye and E. Holmøy (1992): Dynamic Equilibrium Adjustments to a Terms of Trade Disturbance

O. Aukrust (1992): The Scandinavian Contribution to National Accounting

J. Aasness, E. Eide and T. Skjerpen (1992): A Criminometric Study Using Panel Data and Latent Variables

Aaberge and Xuezeng Li (1992): The Trend in Income Inequality in Urban Sichuan and Liaoning, 19861990 Non-convex Budget Sets, Hours Restriction and Nonpecuniary Job-attributes

J.K. Dagsvik (1992): Intertemporal Discrete Choice Random Tastes and Functional Form

H. Vennemo (1993): Tax Reforms when Utility is Composed of Additive Functions Max-stable Processes and Independence from Irrelevant Attributes

J.K. Dagsvik (1993): How Large is the Class of Generalized Extreme Value Random Utility Models?

H. Birkelund, E. Gjelsvik, M. Aaserud (1993): Carbon/ energy Taxes and the Energy Market in Western Europe

E. Bowitz (1993): Unemployment and the Growth in the Number of Recipients of Disability Benefits in Norway

L. Andreassen (1993): Theoretical and Econometric Modeling of Disequilibrium

K.A. Brekke (1993): Do Cost-Benefit Analyses favour Environmentalists?

L. Andreassen (1993): Demographic Forecasting with a Dynamic Stochastic Microsimulation Model

G.B. Asheim and K.A. Brekke (1993): Sustainability when Resource Management has Stochastic Consequences

O. Bjerkholt and Yu Zhu (1993): Living Conditions of Urban Chinese Households around 1990

\section{R. Aaberge (1993): Theoretical Foundations of Lorenz} Curve Orderings

J. Aasness, E. Biørn and T. Skjerpen (1993): Engel Functions, Panel Data, and Latent Variables - with Detailed Results 
I. Svendsen (1993): Testing the Rational Expectation Hypothesis Using Norwegian Microeconomic Data Testing the REH. Using Norwegian Microeconomic Data

E. Bowitz, A. Rødseth and E. Storm (1993): Fiscal Expansion, the Budget Deficit and the Economy: Norway 1988-91 Supply in Italy

T.J. Klette (1993): Is Price Equal to Marginal Costs? An Integrated Study of Price-Cost Margins and Scale Economies among Norwegian Manufacturing Establishments 1975-90

J.K. Dagsvik (1993): Choice Probabilities and Equilibrium Conditions in a Matching Market with Flexible Contracts

T. Kornstad (1993): Empirical Approaches for Analysing Consumption and Labour Supply in a Life Cycle Perspective

T. Kornstad (1993): An Empirical Life Cycle Model of Savings, Labour Supply and Consumption without Intertemporal Separability

S. Kverndokk (1993): Coalitions and Side Payments in International $\mathrm{CO}_{2}$ Treaties

T. Eika (1993): Wage Equations in Macro Models. Phillips Curve versus Error Correction Model Determination of Wages in Large-Scale UK Macro Models

A. Brendemoen and H. Vennemo (1993): The Marginal Cost of Funds in the Presence of External Effects

K.-G. Lindquist (1993): Empirical Modelling of Norwegian Exports: A Disaggregated Approach

A.S. Jore, T. Skjerpen and A. Rygh Swensen (1993): Testing for Purchasing Power Parity and Interest Rate Parities on Norwegian Data

R. Nesbakken and S. Strøm (1993): The Choice of Space Heating System and Energy Consumption in Norwegian Households (Will be issued later)

A. Aaheim and K. Nyborg (1993): "Green National Product": Good Intentions, Poor Device?

K.H. Alfsen, H. Birkelund and M. Aaserud (1993): Secondary benefits of the EC Carbon/ Energy Tax

J. Aasness and B. Holtsmark (1993): Consumer Demand in a General Equilibrium Model for Environmental Analysis

K.-G. Lindquist (1993): The Existence of Factor Substitution in the Primary Aluminium Industry: A Multivariate Error Correction Approach on Norwegian Panel Data

107 S. Kverndokk (1994): Depletion of Fossil Fuels and the Impacts of Global Warming

108 K.A. Magnussen (1994): Precautionary Saving and OldAge Pensions

109 F. Johansen (1994): Investment and Financial Constraints: An Empirical Analysis of Norwegian Firms

110 K.A. Brekke and P. Børing (1994): The Volatility of Oil Wealth under Uncertainty about Parameter Values

111 M.J. Simpson (1994): Foreign Control and Norwegian Manufacturing Performance

112 Y. Willassen and T.J. Klette (1994): Correlated Measurement Errors, Bound on Parameters, and a Model of Producer Behavior

113 D. Wetterwald (1994): Car ownership and private car use. A microeconometric analysis based on Norwegian data
K.E. Rosendahl (1994): Does Improved Environmental Policy Enhance Economic Growth? Endogenous Growth Theory Applied to Developing Countries

115 L. Andreassen, D. Fredriksen and O. Ljones (1994): The Future Burden of Public Pension Benefits. A Microsimulation Study

A. Brendemoen (1994): Car Ownership Decisions in Norwegian Households.

117 A. Langørgen (1994): A Macromodel of Local Government Spending Behaviour in Norway

118 K.A. Brekke (1994): Utilitarism, Equivalence Scales and Logarithmic Utility

119 K.A. Brekke, H. Lurås and K. Nyborg (1994): Sufficient Welfare Indicators: Allowing Disagreement in Evaluations of Social Welfare

T.J. Klette (1994): R\&D, Scope Economies and Company Structure: A "Not-so-Fixed Effect" Model of Plant Performance

Y. Willassen (1994): A Generalization of Hall's Specification of the Consumption function

E. Holmøy, T. Hægeland and Ø. Olsen (1994): Effective Rates of Assistance for Norwegian Industries

K. Mohn (1994): On Equity and Public Pricing in Developing Countries

124 J. Aasness, E. Eide and T. Skjerpen (1994): Criminometrics, Latent Variables, Panel Data, and Different Types of Crime

E. Biøm and T.J. Klette (1994): Errors in Variables and Panel Data: The Labour Demand Response to Permanent Changes in Output

I. Svendsen (1994): Do Norwegian Firms Form Extrapolative Expectations?

127 T.J. Klette and Z. Griliches (1994): The Inconsistency of Common Scale Estimators when Output Prices are Unobserved and Endogenous

K.E. Rosendahl (1994): Carbon Taxes and the Petroleum Wealth

129 S. Johansen and A. Rygh Swensen (1994): Testing Rational Expectations in Vector Autoregressive Models

130 T.J. Klette (1994): Estimating Price-Cost Margins and Scale Economies from a Panel of Microdata

131 L. A. Grünfeld (1994): Monetary Aspects of Business Cycles in Norway: An Exploratory Study Based on Historical Data

132 K.-G. Lindquist (1994): Testing for Market Power in the Norwegian Primary Aluminium Industry

133 T. J. Klette (1994): R\&D, Spillovers and Performance among Heterogenous Firms. An Empirical Study Using Microdata

134 K.A. Brekke and H.A. Gravningsmyhr (1994): Adjusting NNP for instrumental or defensive expenditures. An analytical approach

135 T.O. Thoresen (1995): Distributional and Behavioural Effects of Child Care Subsidies

136 T. J. Klette and A. Mathiassen (1995): Job Creation, Job Destruction and Plant Turnover in Norwegian Manufacturing

137 K. Nyborg (1995): Project Evaluations and Decision Processes

138 L. Andreassen (1995): A Framework for Estimating Disequilibrium Models with Many Markets 

not Clear

T. Skjerpen (1995): Is there a Business Cycle Component in Norwegian Macroeconomic Quarterly Time Series?

141 J.K. Dagsvik (1995): Probabilistic Choice Models for Uncertain Outcomes

M. Rønsen (1995): Maternal employment in Norway, A parity-specific analysis of the return to full-time and part-time work after birth

A. Bruvoll, S. Glomsrød and H. Vennemo (1995): The Environmental Drag on Long- term Economic Performance: Evidence from Norway

T. Bye and T. A. Johnsen (1995): Prospects for a Common, Deregulated Nordic Electricity Market

B. Bye (1995): A Dynamic Equilibrium Analysis of a Carbon Tax

146

O. Thoresen (1995): The Distributional Impact of the Norwegian Tax Reform Measured by Disproportionality

E. Holmøy and T. Hægeland (1995): Effective Rates of Assistance for Norwegian Industries

148 J. Aasness, T. Bye and H.T. Mysen (1995): Welfare Effects of Emission Taxes in Norway

J. Aasness, E. Biøm and Terje Skjerpen (1995): Distribution of Preferences and Measurement Errors in a Disaggregated Expenditure System

150 E. Bowitz, T. Fæhn, L. A. Grünfeld and K. Moum (1995): Transitory Adjustment Costs and Long Term Welfare Effects of an EU-membership - The Norwegian Case

151 I. Svendsen (1995): Dynamic Modelling of Domestic Prices with Time-varying Elasticities and Rationa Expectations

152 I. Svendsen (1995): Forward- and Backward Looking Models for Norwegian Export Prices

153 A. Langørgen (1995): On the Simultaneous Determination of Current Expenditure, Real Capital, Fee Income, and Public Debt in Norwegian Local Government

154 A. Katz and T. Bye(1995): Returns to Publicly Owned Transport Infrastructure Investment. A Cost Function/ Cost Share Approach for Norway, 1971-1991

K. O. Aarbu (1995): Some Issues About the Norwegian Capital Income Imputation Model
P. Boug, K. A. Mork and T. Tjemsland (1995): Financial Deregulation and Consumer Behavior: the Norwegian Experience

157 B. E. Naug and R. Nymoen (1995): Import Price Formation and Pricing to Market: A Test on Norwegian Data

R. Aaberge (1995): Choosing Measures of Inequality for Empirical Applications.

T. J. Klette and S. E. Førre (1995): Innovation and Job Creation in a Small Open Economy: Evidence from Norwegian Manufacturing Plants 1982-92

S. Holden, D. Kolsrud and B. Vikøren (1995): Noisy Signals in Target Zone Regimes: Theory and Monte Carlo Experiments

161 T. Hægeland (1996): Monopolistic Competition, Resource Allocation and the Effects of Industrial Policy

S. Grepperud (1996): Poverty, Land Degradation and Climatic Uncertainty

163 S. Grepperud (1996): Soil Conservation as an Investment in Land

K. A. Brekke, V. Iversen and J. Aune (1996): Soil Wealth in Tanzania Potential Demand for Alternative Fuel Vehicles

J.K. Dagsvik (1996): Consumer Demand with Unobservable Product Attributes. Part I: Theory

167 J.K. Dagsvik (1996): Consumer Demand with Unobservable Product Attributes. Part II: Inference

168 R. Aaberge, A. Björklund, M. Jäntti, M. Palme, P. J. Pedersen, N. Smith and T. Wennemo (1996): Income Inequality and Income Mobility in the Scandinavian Countries Compared to the United States

K. Nyborg (1996): Some Norwegian Politicians' Use of Cost-Benefit Analysis

170 E. Berg, S. Kverndokk and K. E. Rosendahl (1996): Market Power, International $\mathrm{CO}_{2}$ Taxation and Petroleum Wealth

171 Rolf Aaberge, Ugo Colombino and Steinar Strøm (1996): Welfare Effects of Proportional Taxation: Empirical Evidence from Italy, Norway and Sweden

J.K. Dagsvik (1996): Dynamic Choice, Multistate Duration Models and Stochastic Structure 


\section{Discussion Papers}

Statistics Norway Research Department P.O.B. 8131 Dep.

N-0033 Oslo

Tel.: + $47-22864500$ Fax: + $47-22111238$

ISSN 0803-074X 